\title{
Update on glasdegib in acute myeloid leukemia - broadening horizons of Hedgehog pathway inhibitors
}

\author{
CYRIL FERSING ${ }^{1,2 *}$ \\ FANNY MATHIAS 3,4 \\ ${ }^{1}$ University of Montpellier, Montpellier \\ Cancer Institute (ICM), Montpellier, France \\ ${ }^{2}$ Institut des Biomolécules Max Mousseron \\ UMR 5247, CNRS, Université de Montpellier \\ ENSCM, UFR des Sciences Pharmaceutiques \\ et Biologiques, Montpellier Cedex, France
}

${ }^{3}$ Aix Marseille Univ, Pharmacy Department Hôpital Nord, Assistance Publique Hôpitaux de Marseille, Marseille, France

${ }^{4}$ Aix Marseille Univ, CNRS, ICR UMR 7273, Equipe Pharmaco-Chimie Radicalaire Faculté de Pharmacie, CS30064, 13385 Marseille Cedex 05, France

Accepted January 26, 2021

Published online April 16, 2021

\begin{abstract}
Numerous new emerging therapies, including oral targeted chemotherapies, have recently entered the therapeutic arsenal against acute myeloid leukemia (AML). The significant shift toward the use of these novel therapeutics, administered either alone or in combination with intensive or low-intensity chemotherapy, changes the prospects for the control of this disease, especially for elderly patients. Glasdegib, an oral Hedgehog pathway inhibitor, showed satisfactory response rates associated with moderate toxicity and less early mortality than standard induction regimens in this population. It was approved in November 2018 by the FDA and in June 2020 by the EMA for use in combination with low-dose cytarabine as a treatment of newly-diagnosed AML in patients aged $\geq 75$ and/or unfit for intensive induction chemotherapy. The current paper proposes an extensive, up-to-date review of the preclinical and clinical development of glasdegib. Elements of its routine clinical use and the landscape of ongoing clinical trials are also stated.
\end{abstract}

Keywords: glasdegib, PF-04449913, PF-913, acute myeloid leukemia, Hedgehog pathway, smoothened

\section{INTRODUCTION}

The hedgehog $(\mathrm{HH})$ intracellular signaling pathway, first described in Drosophila in 1980 (1), has a significant role in normal embryonic development and adult stem cell persistence (2-4). The physiological HH pathway (Fig. 1) is dependent upon 3 known human ligands, triggering a concentration- and gradient-dependent response (3). They are lipid-modified secreted proteins named Sonic $\mathrm{HH}(\mathrm{SHH})$, Indian $\mathrm{HH}(\mathrm{IHH})$ and Desert $\mathrm{HH}(\mathrm{DHH})$ (4). These ligands can bind to negative-regulator receptors named Patched (PTCH1 and PTCH2, 12-pass transmembrane proteins) (5), resulting in the derepression of the G-protein-like transducer Smoothened (SMO, a 7-pass transmembrane protein) (6). Intracellular glioma zinc finger transcription factors (GLI1, GLI2 and GLI3) are then activated by SMO and promote the expression of several HH-pathway-related genes, such as BCL2, cMYC and SNAIL (7-9). Overall, expression levels of GLI1 are well correlated with the HH pathway

\footnotetext{
*Correspondence; e-mail: cyril.fersing@icm.unicancer.fr
} 


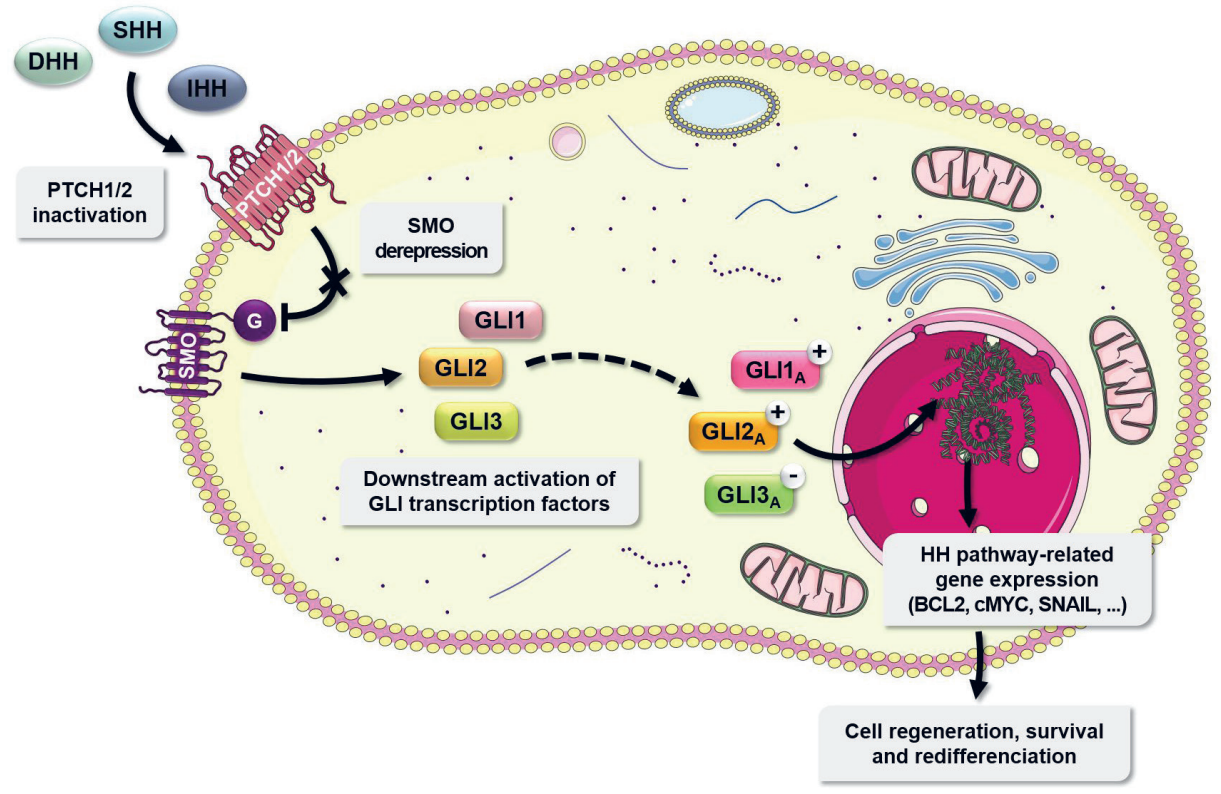

Fig. 1. Simplified physiological HH pathway signaling.

activity, although the expression of this factor can also be enhanced by several SMO-independent mechanisms (10).

$\mathrm{HH}$ pathway and GLI abnormal signaling are associated with dysregulation of cell regeneration and redifferentiation. Thus, these modifications can be found in several types of cancer (11). Among these diseases, the role of deviant $\mathrm{HH}$ signaling in hematological cancers has been particularly emphasized, especially in myeloid malignancies (12-14). In acute myeloid leukemia (AML), HH pathway overexpression was objectified in myeloblastic cells $(15,16)$ and was associated with cell survival, chemoresistance and radiotherapy resistance (17-21). Therefore, the HH pathway and, more specifically, the SMO protein appeared as a promising pharmacological target, which may be inhibited by small molecules. Numerous derivatives have been developed as SMO inhibitors (22), the most widely used in oncology being vismodegib, sonidegib and glasdegib. Although preclinical studies have shown significant efficacy of vismodegib and sonidegib in hematological cancer models $(21,23,24)$, these two drugs had little clinical evaluation in patients with leukemic pathologies (25). On the other hand, glasdegib has been studied more intensively as a potential treatment in acute myeloid leukemia. Following the positive results of phase II clinical trials (26), glasdegib received its first approval in the USA on 21 November 2018 for its use in the combination with low dose cytarabine (LDAC) in newly-diagnosed AML patients $\geq$ 75 years or with comorbidities that contraindicate the use of intensive induction chemotherapy (IC) $(27,28)$. This approval was almost simultaneous with the authorization of ivosidenib and gilteritinib in the treatment of AML and came one year after the approval of midostaurin, enasidenib and gemtuzumab ozogamycin as therapeutic alternatives in 
AML. In this context, the way in which these molecules should be used and their respective advantages have given rise to much debate (29-31). The purpose of this review is to provide a comprehensive update on glasdegib as an active ingredient, from its discovery to the practical considerations of its therapeutic use in AML, with particular emphasis on its clinical evaluation.

\section{PHARMACOLOGY AND PRECLINICAL STUDIES}

Glasdegib, formerly PF-04449913 or PF-913, was initially identified by Munchhof et al. among a small series of benzimidazole-based Smoothened inhibitors (32). It resulted from the optimization of a former hit molecule with suboptimal physicochemical properties (33). In addition to preserved in vitro efficacy $\left(I C_{50}\right.$ in Gli-luciferase reporter assay is $5 \mathrm{nmol}$ $\mathrm{L}^{-1}$ ), glasdegib also displayed good in vitro microsomal stability, $9 \%$ free fraction in plasma and promising physicochemical properties (Table I). According to in vivo pharmacokinetic studies in rats and dogs, glasdegib was predicted to have good PK properties in humans ( $1.03 \mathrm{~mL} \mathrm{~min}^{-1} \mathrm{~kg}^{-1}$ plasma clearance, $2.7 \mathrm{~L} \mathrm{~kg}^{-1}$ volume of distribution, $30 \mathrm{~h}$ half-life and $55 \%$ oral bioavailability) along with excellent potency.

In a preclinical study involving a PTCH1+/-p53 mouse model of medulloblastoma and human patient-derived xenograft models, glasdegib displayed potent dose-dependent inhibition of the $\mathrm{HH}$ pathway, resulting in stable tumor regression (34). Glasdegib-treated medulloblastoma allografts had reduced levels of Gli1 gene expression and downregulation of genes linked to the Hh signaling pathway. This GLI1 downregulation is consistent

Table I. Early in vitro data and preclinical in vivo pharmacokinetics of glasdegib

\begin{tabular}{|c|c|c|c|}
\hline & \multicolumn{3}{|l|}{ In vitro properties } \\
\hline & Molar mass $\left(\mathrm{g} \mathrm{mol}^{-1}\right)$ & \multicolumn{2}{|c|}{374} \\
\hline & Measured $\log D$ & \multicolumn{2}{|c|}{2.48} \\
\hline & Gli-luciferase reporter in C3H10T1/2 IC $C_{50}(\mathrm{nmol} \mathrm{L}-1)$ & \multicolumn{2}{|c|}{5} \\
\hline & Human microsomes CLi (mL $\left.\min ^{-1} \mathrm{~kg}^{-1}\right)$ & \multicolumn{2}{|c|}{6.3} \\
\hline & Human plasma protein binding ( $\%$ free) & \multicolumn{2}{|c|}{9.1} \\
\hline$\lambda$ & Ames test & \multicolumn{2}{|c|}{ Negative } \\
\hline $1 /$ & Micronucleus assay & \multicolumn{2}{|c|}{ Negative } \\
\hline$N^{\prime \prime}$ & In vivo pharmacokinetics & In rat & In dog \\
\hline & $\mathrm{CL}\left(\mathrm{mL} \mathrm{min}^{-1} \mathrm{~kg}^{-1}\right)$ & 31 & 3.9 \\
\hline IUPAC name: & $V_{\mathrm{ss}}$ & 4.8 & 4.3 \\
\hline $1-[(2 R, 4 R)-2-(1 H$-benzimidazol- & $T_{1 / 2}(\mathrm{~h})$ & 1.4 & 2.9 \\
\hline -3-(4-cyanophenyl)urea & $F(\%)$ & 33 & 68 \\
\hline
\end{tabular}


with the results subsequently obtained in clinical trials $(35,36)$, however, glasdegib's mode of action remained unclear at the cellular and molecular level. Thus, the pharmacology of this drug was studied on a Drosophila model that confirmed its SMO inhibition activity (37). As a consequence, blood cell homeostasis was disrupted in a way that could cause, in humans, leukemic stem cells (LSC) to exit from the bone marrow. These LSC, known to persist beyond conventional treatment cessation and to result in a relapse in myeloid diseases such as AML $(38,39)$, could enter the bloodstream and become sensitive to therapeutic agents $(12,40)$. Similar results were obtained in vitro, also presenting bone marrow stromal cells as a possible target of Smo inhibitors to decrease the quiescent LSC population (41). In an AML xenograft mouse model, glasdegib showed synergistic action with LDAC in inhibiting tumor growth and limiting the percentage of CD45+/CD33+ blasts in the bone marrow (41). As previously proposed, glasdegib-treated AML cells showed increased sensitivity to chemotherapeutic agents such as cytarabine, highlighting the benefit of glasdegib plus chemotherapy association. Effects of glasdegib on LSC quiescence, survival and self-renewal were also investigated on mice intrahepatically transplanted with blast crisis chronic myeloid leukemia (CML) LSCs (42). Mice were treated for 14 days by daily oral gavage with dasatinib alone $\left(50 \mathrm{mg} \mathrm{kg}^{-1}\right)$ or glasdegib $\left(100 \mathrm{mg} \mathrm{kg}^{-1}\right)$ with or without dasatinib $\left(50 \mathrm{mg} \mathrm{kg}^{-1}\right)$. Combination treatment with glasdegib and dasatinib revealed a significant decrease in LSC hepatic engraftment compared with glasdegib or dasatinib alone. Cell cycle analysis also demonstrated a reduction in quiescent human leukemic cells in the peripheral blood and in the bone marrow following SMO inhibitor treatment (43). Like in the previous study, Chaudhry et al. documented the benefits of using glasdegib in an association, emphasizing the key role of Gli3r for the therapeutic effect of SMO antagonists in AML (44). They demonstrated that GLI3 gene expression was epigenetically silenced in most AML, causing glasdegib ineffectiveness. However, treatment with hypomethylating agents (HMA), such as decitabine, restored GLI3 expression and therefore glasdegib efficacy. Similar results were also obtained concerning GLI2 expression $(45,46)$. Some clinical trials' protocols presented subsequently are based on this mechanistic rationale for combining chemotherapeutic agents and SMO antagonists in AML.

\section{CLINICAL EVALUATION}

\section{Phase I}

After a first-in-patient preliminary evaluation (47), Martinelli et al. reported an openlabel, multi-center phase Ia dose-escalation study (NCT00953758) to assess first-cycle dose-limiting toxicities (DLTs) and the recommended phase II dose (RP2D) of glasdegib $(35,47)$. Forty-seven patients have been enrolled at doses from $5 \mathrm{mg}$ to $600 \mathrm{mg}$ orally once daily, for 1 to 537 days. Patients had refractory, resistant, or intolerant selected hematologic malignancies such as AML $(n=28)$, CML $(n=5)$, myelodysplastic syndrome (MDS, $n=6)$, myelofibrosis (MF, $n=7$ ) or chronic myelomonocytic leukemia (CMML, $n=1$ ). One of the AML patients achieved complete remission with incomplete blood count recovery (CRi, bone marrow blast count decreased from 92 to $1 \%$ ), seven AML patients had a stable bone marrow blast count, one patient with low-risk MDS achieved a significant reduction in spleen size and a hematologic improvement in platelets (from 98.5 to $369 \times 10^{9} \mathrm{~L}^{-1}$ ) and neutrophils, five patients with MF attained stable disease, and one patient with T3151 lymphoid 
blast crisis CML achieved a major cytogenetic response with loss of the T3151 mutation. The gene expression profile analysis of bone marrow LSC progenitors evidenced that glasdegib triggered $\mathrm{HH}$ pathway genes (Gas1, Kif 27) up-regulation (48) and chemoresistance genes (ABCA2, Bcl2) downregulation (49). Overall, glasdegib showed preliminary clinical activity in nearly half of the patients in the study. Four patients discontinued the study due to a treatment-related adverse event (TRAE): hemorrhagic gastritis (10 mg group), decreased appetite (40 mg group), peripheral oedema ( $400 \mathrm{mg}$ ) and decreased weight (600 $\mathrm{mg}$ group). The majority of AEs were of G1/2 severity, including dysguesia (28 \%), decreased appetite (19\%), alopecia (15\%), diarrhea (13\%), nausea (13\%) and vomiting (11 \%). Glasdegib PK data indicated a dose-proportional profile, with a $T_{\max }$ of 1-2 hours, a mean half-life of about 24 hours and a large volume of distribution (250-480 L). Steady-state was achieved in 8 days and the median accumulation ratio ranged from 1.3 to 2.9. Based on the safety, tolerability, pharmacodynamic analysis and preliminary clinical activity reported, the RP2D for treatment with glasdegib was established to be $200 \mathrm{mg}$ or lower once daily.

In view on the encouraging results of this first study, Minami et al. reported the partial results of an open-label, multicenter phase I trial (NCT02038777) of glasdegib in 13 Japanese patients with AML $(n=7)$, MDS $(n=4)$, CMML $(n=1)$ or MF $(n=1)(50)$. Glasdegib was administered orally once a day at $25 \mathrm{mg}, 50 \mathrm{mg}$ or $100 \mathrm{mg}$ for 36 to 332 days and didn't cause any DLT, although treatment was permanently discontinued in 4 patients due to AE ( 3 at $50 \mathrm{mg}$ and 1 at $100 \mathrm{mg}$ ). Observed AEs were very consistent with those reported by Martinelli et al. (35). Preliminary clinical activity data showed that 1 AML patient achieved morphological complete remission (CR) in the $100 \mathrm{mg}$ group and 4 AML patients (1 each in the $20 \mathrm{mg}$ and 50 group, 2 in the $100 \mathrm{mg}$ group) achieved stable disease. One MDS patient in the $100 \mathrm{mg}$ group achieved marrow complete remission and 2 MDS patients (1 each in the $25 \mathrm{mg}$ and $100 \mathrm{mg}$ group) achieved stable disease. Glasdegib PK parameters were comparable to those previously reported (dose-proportional kinetics, $T_{\max }=2-4 \mathrm{~h}, T_{1 / 2}=20.7 \pm 7.7 \mathrm{~h}$ ).

The first combination of glasdegib with standard chemotherapy in patients was reported by Savona et al. (51). In an open-label, multicenter, dose-escalation, phase Ib study (BRIGHT AML 1003, NCT01546038), glasdegib $100 \mathrm{mg}$ or $200 \mathrm{mg}$ was administered orally, once a day during 2-567 days, in combination with LDAC $(n=23, \operatorname{arm} \mathrm{A})$, decitabine $(n=7$, arm B) or cytarabine/daunorubicin $(n=22$, arm C). Most patients had a diagnosis of AML $(87 \%, 71 \%$ and $91 \%$ of patients in arm A, B and C, respectively); others were MDS patients. In this population, a clinically beneficial response was observed in $2(10 \%), 3(60 \%)$ and $12(60 \%)$ patients in arms A, B and C, respectively. However, these response rates were not significantly different than those expected with standard treatment alone. Overall survival (OS) was 4.4, 11.5 and 34.7 months in arm A, B and C, respectively. Analysis of gene mutation profiles in responders and non-responders did not indicate that clinical response could be predicted by any particular mutation profile. In the same way, minimal or inconsistent changes were evident in circulating cytokines in these patients. No DLTs were observed in arm A and arm B, but 1 DLT (grade 4 neuropathy) occurred in arm C. The most common non-hematologic TRAEs were mostly graded 1 and 2 in all arms. Muscle spasms, considered the most frequent TRAE, were observed in 49 to $76 \%$ of patients. Based on the tolerability, efficacy and PK profile of glasdegib in combination with chemotherapy regimens, the authors selected an RP2D of $100 \mathrm{mg}$ daily as a basis for further evaluations in these patient populations. 
To compensate for the low number of patients with MDS in this study, another openlabel phase Ib clinical trial aimed to enroll more MDS patients. In this BRIGHT MDS \& AML 1012 study (NCT02367456), early trends suggested an acceptable safety profile for the combination of glasdegib $100 \mathrm{mg}$ daily with azacytidine (AZA) $75 \mathrm{mg} \mathrm{m}^{-2}$ day 1-7 every 25 days $(52,53)$. The number of CR ( 3 for 12 patients in 2015, 5 for 30 patients in 2019) appeared favorable in comparison with AZA alone. Analysis of early hematopoietic recovery and transfusion independence showed that early platelet recovery was correlated with response to treatment (54). Among patients with MDS and AML (both $n=30$ in 2019), respectively, $54 \%(7 / 13)$ and $64 \%(9 / 14)$ of evaluable transfusion-dependent patients at baseline became transfusion-independent after an average treatment duration of 5 months. In addition to this early marrow recovery, the glasdegib + ASA combination did not seem to impact negatively the health-related quality of life of patients (55). Definitive conclusions of this study are still pending.

Gerds et al. reported a single-arm, lead-in cohort, open-label phase Ib/II trial (NCT02226172) of glasdegib in patients with primary or secondary MF previously treated with at least $1 \mathrm{JAK}$ inhibitor (56). Twenty-one patients received $100 \mathrm{mg}$ glasdegib orally for up to 24 weeks. Approximately $40 \%$ of patients achieved $>20$ to $30 \%$ reduction in symptoms, suggesting that glasdegib could have a significant benefit in improving MF-related clinical manifestations. However, mean spleen volume measured by MRI or CT at weak 24 suggested this treatment may not sustainably decrease spleen volume in this patient population (mean percentage change from baseline in spleen volume was $+10.92 \%$; 3 patients with stabilization or reduction in spleen size). All 21 patients experienced one or more TRAE, causing permanent treatment discontinuation for $12(57.1 \%)$ patients, mostly due to muscle spasms $(n=6)$ and dysgeusia $(n=3)$. Although the frequencies of TRAEs in this population were higher than those reported in previous studies, the toxicity profile of glasdegib was considered manageable. The authors proposed to consider alternative dosing schedules as a strategy to increase tolerability of glasdegib in similar populations.

Glasdegib was also evaluated in 23 patients with various advanced solid tumors, through an open-label, multicenter, phase I study (NCT01286467, 36). Eight patients achieved stable disease and glasdegib was well tolerated at doses of 80-320 mg, once daily. TRAEs and PK parameters were consistent with previous statements.

\section{Phase II}

After the phase I studies of glasdegib in myeloid malignancies, this SMO inhibitor was evaluated in combination within larger patient cohorts. In an open-label, phase II, multicenter trial (BRIGHT AML 1003 "intensive arm", NCT01546038), previously untreated patients with AML $(n=66)$ or high-risk MDS $(n=5)$ received glasdegib $100 \mathrm{mg}$ orally once daily in 28-days cycles (range 10-501 days), with intravenous daunorubicin $60 \mathrm{mg} \mathrm{m}^{-2}$ on days $1-3$ and continuous intravenous cytarabine $\left(100 \mathrm{mg} / 1.73 \mathrm{~m}^{2}\right)$ on days $1-7$ of every cycle (57). Of the 69 patients included in the full analysis set, $46.6 \%$ (80 \% CI 38.7-54.1) achieved CR, among which $40.0 \%$ (31.9-48.1) of patients aged $\geq 55$ years and $88.9 \%$ (75.5$100.0)$ of patients aged $<55$ years. These values are within the range of those reported for other AML therapies, or even slightly better (58-60). The median duration of CR was 94 (range 1-480) days in all patients and $103(1-480)$ and 50 (1-268) days in patients aged $\geq 55$ years and $<55$ years, respectively. These results have certainly contributed to the positioning 
of glasdegib as a therapeutic alternative in AML for elderly populations (61). Overall, 35 (54.7\%) AML patients and 2 (40\%) MDS patients achieved CR/CRi. The combination of glasdegib with cytarabine and daunorubicin caused mostly low-grade diarrhea and nausea, however, more than $80 \%$ of patients experienced grade 3 adverse events (AEs). Across all patients, 14 (20.3\%) and 25 (36.2 \%) patients permanently or temporarily, respectively, discontinued study treatments (glasdegib and/or cytarabine/daunorubicin) due to AEs. Five (7.2\%) patients had dose reductions due to AEs. Expression levels of several genes were investigated and showed that FLT3 mutations and high PTCH1 expression levels were correlated with a better response (62). Conversely, mutations in TP53, NF1 or CREBBP were associated with a negative response (63).

The same authors also reported the results from another portion of the aforementioned phase II clinical trial, comparing low dose cytarabine (LDAC) with or without glasdegib in AML and MDS patients under randomized conditions (26). In this section of the BRIGHT AML 1003 trial (NCT01546038), LDAC was administered subcutaneously for 10 days per 28-day cycles, as monotherapy for 41 patients and associated with $100 \mathrm{mg}$ glasdegib administered orally every day of the cycle for 84 patients (Fig. 2). In each group, over half of the patients were aged $>75$ years. After the follow-up period ( 21.7 months and 20.1 months on average for glasdegib/LDAC arm and LDAC arm, respectively), the median (80 $\%$ CI) OS was 8.8 (6.9-9.9) months with combination therapy and 4.9 (3.5-6.0) months with LDAC alone. This significant OS improvement is reflected in a $49 \%$ reduction in the risk of death for patients treated with glasdegib/LDAC, compared to LDAC alone. These data have been refined by treatment-response and exposure-response analyses, also specifying that variability in glasdegib exposures did not impact the risk of death (64). CR was achieved in $17 \%(n=15)$ and $2.3 \%(n=1)$ patients in glasdegib/LDAC arm and LDAC arm, respectively. Noteworthy, the CR rate in the LDAC arm was quite lower than previously reported in other trials (65-67), with no evident reason. The median time to CR among patients receiving the combination therapy was 1.9 months, with a 9.9-month median duration of CR. In the MDS group, patients treated with combination therapy $(n=10)$ achieved a $22.8 \%$ reduction in the risk of death relative to LDAC alone $(n=6)$, which was considered as an encouraging result despite the small sample size. The addition of glasdegib to LDAC was generally well tolerated, with a manageable safety profile even in elderly patients. Nevertheless, 9 out of 10 and 3 out of 6 patients permanently discontinued study treatments due to TRAEs in combination therapy arm and LDAC arm, respectively.

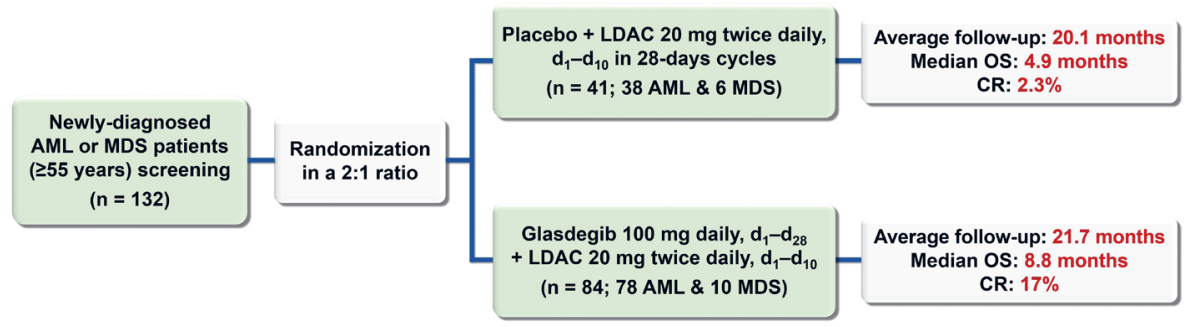

Fig. 2. Design and main results of the randomized, placebo-controlled section of the phase 2 BRIGHT AML 1003 study. 
This first randomized phase II study highlighted the combination of glasdegib with LDAC as a compelling therapeutic approach, especially for AML patients ineligible for IC (68). Long-term outcomes in the same patients (43.4 months and 42.0 months follow-up period on average for glasdegib/LDAC arm and LDAC arm, respectively) confirmed the previous results (median OS $=8.3$ vs. 4.3 months) (69). A post-hoc analysis also showed that the addition of glasdegib to LDAC vs. LDAC alone was associated with improved OS both in patients with de novo AML and secondary AML (70). Overall, although other combination therapies like HMA with venetoclax have been associated with much higher response rates in AML (71), the clinical efficacy and good safety profile of the glasdegib/LDAC combination assessed in this study were pivotal evidence for glasdegib regulatory approval (72). Late follow-up analyses remained consistent with the primary findings (73). In 2020, Cortes et al. published a post-hoc analysis suggesting possible clinical benefits of glasdegib in the absence of CR (74), as the addition of glasdegib to the LDAC tend to improve OS versus LDAC alone (median OS $=5.0$ and 4.1, respectively) in patients who did not achieve CR. Moreover, durable recovery of the absolute neutrophil count, hemoglobin and platelets was observed in more patients receiving combination therapy, though improved OS could not be obviously correlated to the reach of a specific blood count threshold (75).

Tremblay et al. reused the data of the previous study and have resorted to indirect or simulated treatment comparison methods to compare the effectiveness of glasdegib + LDAC association with HMAs in AML (76). Published clinical trials evaluating AZA or decitabine $v s$. LDAC in elderly AML patients ineligible for IC were used to obtain comparative data. Despite the risk of imperfect adjustment depending on the model applied, this indirect comparison compensates for the absence of direct, head-to-head trial results. Based on this methodology, glasdegib associated with LDAC tended to demonstrate consistently favored OS hazard ratios (HR) over either AZA or decitabine ( $\mathrm{HR}=0.424$; $95 \% \mathrm{CI}=0.228-0.789$ and $\mathrm{HR}=0.505 ; 95 \% \mathrm{CI}=0.269-0.949$, respectively). A second study performed an indirect treatment comparison between glasdegib + LDAC and AZA depending on bone marrow blasts count (77). Both unadjusted HRs and HRs corrected for the potential imbalances at baseline between the trials suggested that glasdegib + LDAC association may be preferred over AZA, regardless of bone marrow blasts count, in previously untreated, chemotherapy-ineligible AML patients.

Glasdegib was also evaluated in a single-center, open-label phase II study (NCT01842646) as a monotherapy (100 mg daily oral dose during 28 days, up to 4 cycles) in 35 patients (median age $=73$ years) with MDS, CMML or AML $(74,15$ and $11 \%$, respectively) who have experienced refractory disease, progression or relapse following prior HMA therapy $(78,79)$. Although the treatment was safe and well-tolerated, only $6 \%$ of patients $(n=2)$ achieved an objective response. Nineteen patients had stable disease (median OS = 20.6 months), however, the limited activity of glasdegib as a single agent supports its greater interest in combination therapy, as previously stated (80).

Finally, Kent et al. conducted a dual-center phase II study evaluating the ability of glasdegib to prevent post-allogeneic stem cell transplantation (ASCT) relapse in 31 AML and MDS patients at high risk for this outcome (81). Patients received $100 \mathrm{mg}$ oral glasdegib daily for 28-day cycles, starting from day 28 to 100 post-ASCT and continuing for 1 year in the absence of relapse or intolerance. The median time on treatment before permanent discontinuation was 142 days (range, 28-336 days). More than $90 \%$ of patients $(n=28)$ experienced at least $1 \mathrm{AE}$ attributable to glasdegib and half of the patients $(n=16)$ experienced 
at least 1 grade $\geq 2$ AE. Two-thirds of patients $(n=19)$ had glasdegib interruptions because of AEs and 5 had dose reductions, mostly because of cramping or myalgia. The significant quality-of-life issues objectified in this study and caused by glasdegib, possibly due in part to interactions with the multiple concomitant medications routinely administered post-ASCT, suggested a probable risk of poor compliance with treatment. Overall, among these 31 patients, 1 - and 2-year OS rates were 64.5 and $46.8 \%$, respectively. Relapse-free survival rates were 41.9 and $31.5 \%$, respectively. Eight patients had a measurable residual disease relapse at median time of 180.5 days post-ASCT and 17 patients experienced a morphological relapse at a median time of 333 days post-ASTC. This pilot study, although not randomized, suggested limited ability for glasdegib to prevent relapse in a high-risk post-ASCT setting and highlighted a non-optimal tolerance profile that could affect both adherence and quality of life.

\section{Phase III}

The BRIGHT AML 1019 trials (NCT03416179) were designed as two independent, phase III, randomized (1:1), double-blind studies evaluating the efficacy of oral glasdegib $100 \mathrm{mg}$ once daily or placebo plus one or two standard chemotherapy regimens in adults with untreated AML (Fig. 3) $(82,83)$. In the intensive study $(n=200: 200)$, patients received glasdegib or placebo for up to two years or until disease progression, treatment failure, hematological relapse, toxicity, elimination of measurable/minimal residual disease, patient refusal or death. Glasdegib was combined with cytarabine and daunorubicin $\left({ }^{\prime} 7+3^{\prime}\right.$ induction therapy followed by 1 to 428 -day cycles of consolidation therapy with cytarabine alone). In the nonintensive study $(n=160: 160)$, patients received glasdegib or placebo plus AZA given subcutaneously or intravenously for 7 days in 28-day cycles, for at least 6 cycles or until disease progression, toxicity, patient refusal or death. Assignment to the intensive or nonintensive study was decided by the investigator.

In each study, eligible patients could receive allogeneic stem cell transplantation and may continue glasdegib or placebo up to 2 years after randomization. The results of this

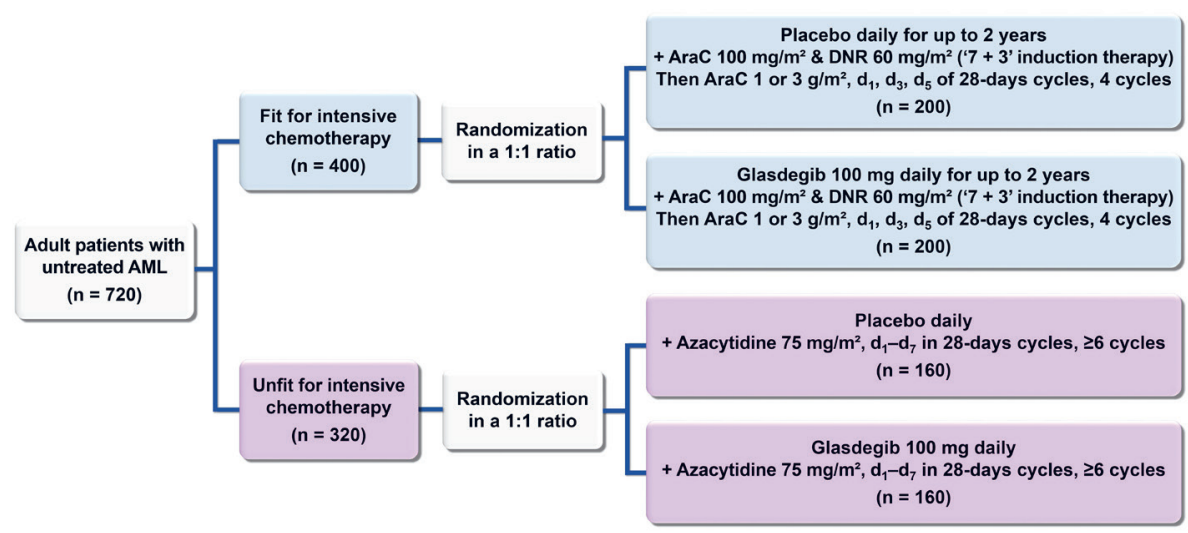

Fig. 3. Design of the randomized, placebo-controlled phase 3 BRIGHT AML 1019 study. 


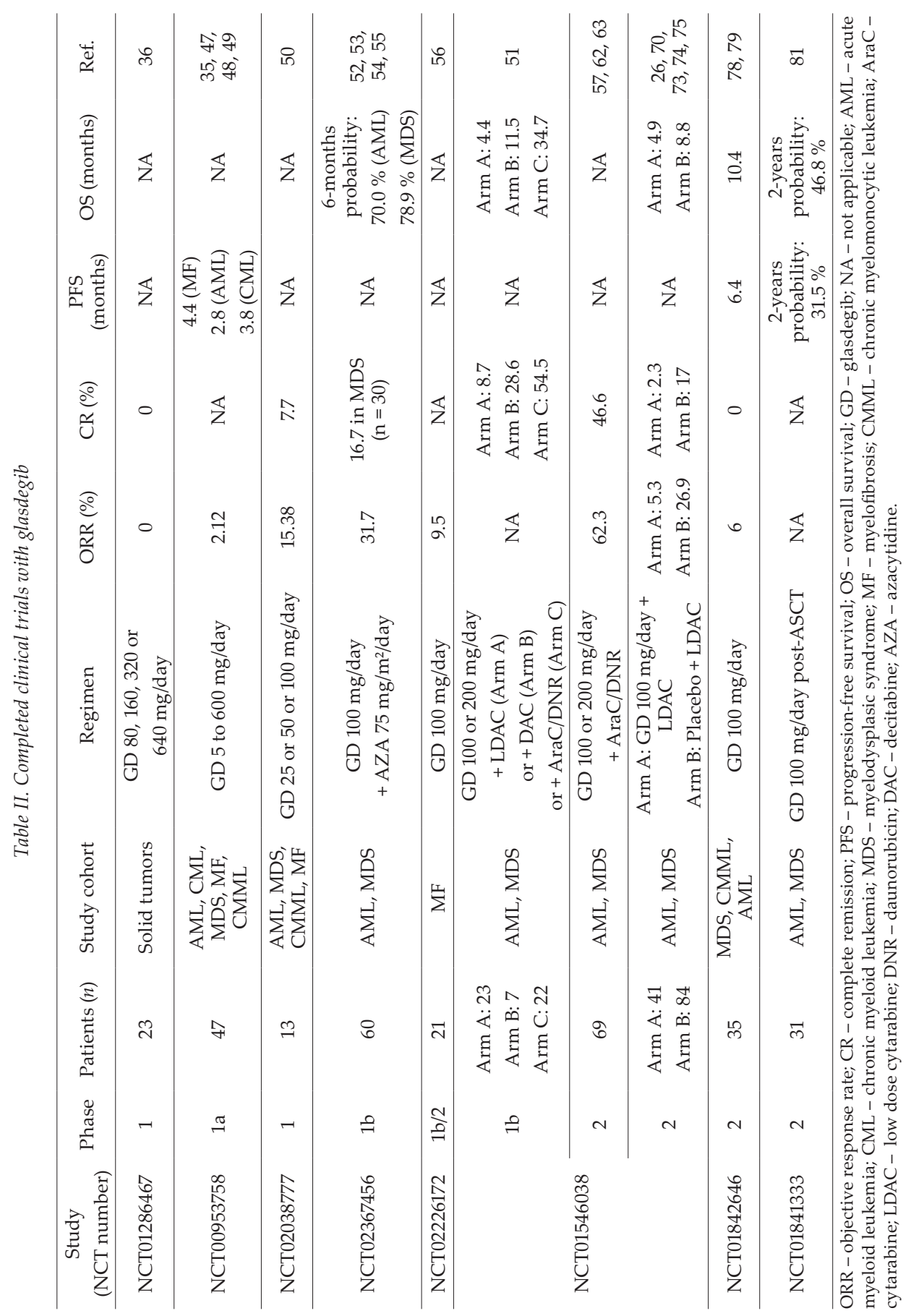


study, when available, may support the expansion of the current registration of glasdegib to include treatment of AML patients in combination with cytarabine plus daunorubicine or AZA, in addition to its already approved indication. A summary of the main results obtained from clinical trials with glasdegib is given in Table II.

\section{Pharmacokinetics and drugs interactions}

Using samples collected from initial phase I and II studies $(35,36,51)$, Lin et al. developed a PK model to characterize glasdegib kinetic behavior in patients and to predict the sources of variability in its PK parameters $(84,85)$. Data from 269 patients with various haematological or solid tumor malignancies (median age and weight was 69 years and $78.6 \mathrm{~kg}$; median creatinine renal clearance was $80.9 \mathrm{~mL} \mathrm{~min}^{-1}$; normal hepatic function in $81 \%$ patients) showed that glasdegib followed a two-compartment first-order absorption model. Age, sex, race and hepatic function were not found to be significant covariates on glasdegib PK parameters, unlike the baseline percentage of bone marrow blasts, creatinine renal clearance and use of CYP3A4 inhibitors. However, these variation factors were not considered to alter glasdegib PK in a clinically meaningful way at the recommended $100 \mathrm{mg}$ daily dose.

Initial clinical trials did not measure oral bioavailability of glasdegib, thus, Shaik et al. ran an open-labeled, phase I, randomized, 2-sequence, 2-treatment, 2-period, crossover study in healthy volunteers under fasting conditions to quantify this parameter (NCT03270878, 86). Drug plasma concentrations were monitored by HPLC-MS in 12 subjects who received either $100 \mathrm{mg}$ p.o. or $50 \mathrm{mg}$ i.v. glasdegib. After a washout period of 6 days or more, the subjects received the treatment they did not get during the first period. The absolute oral bioavailability of glasdegib was $77.12 \%$ and other PK parameters values were comparable to those measured in the previous phase I trials $\left(T_{\max }=1.52 \mathrm{~h} ; V_{\mathrm{d}}=199.6\right.$ $\mathrm{L} ; T_{1 / 2}=14.3 \mathrm{~h}$ ). The same authors also showed, through two other phase I open-label studies on healthy subjects, that neither the formulation (small- or large-particle size tablets and oral solution), nor the food intake, nor the coadministration of an acid-reducing agent (rabeprazole) had a clinically meaningful impact on oral bioavailability and pharmacokinetics of glasdegib $(87,88)$.

Other PK parameters of glasdegib were studied by Lam et al. in a single-dose, open-label phase I clinical trial (NCT02110342), through the administration of ${ }^{14} \mathrm{C}$-glasdegib (100 mg oral dose containing $\sim 3,7 \mathrm{kBq}$ ) in 6 healthy volunteers (89). The mean $T_{\max }$ in plasma was measured at $0.75 \mathrm{~h}$ post-administration and the mean $T_{1 / 2}$ of total radioactivity was $14.2 \mathrm{~h}$, slightly shorter than previously stated (50). Hepatic metabolism, with particular involvement of CYP3A4, was confirmed as the main clearance pathway of glasdegib, primarily forming hydroxy, $\mathrm{N}$-desmethyl and $\mathrm{N}$-glucuronide primary metabolites. These components represented $<10 \%$ of circulating radioactivity in plasma. Renal and faecal routes tended to contribute almost equally to glasdegib elimination ( 49 and $42 \%$ of the administered dose, respectively).

Effects of strong CYP3A4 inhibitors on the metabolism of glasdegib were studied in depth by Shaik et al. in a crossover protocol (NCT01749085) where healthy volunteers received a single oral administration of $200 \mathrm{mg}$ glasdegib, in either a fasted or fed state, spaced by an 8 -day washout. Subsequently, subjects received $400 \mathrm{mg}$ ketoconazole by oral route once daily for 7 days and $200 \mathrm{mg}$ glasdegib on day 4 (90). Administration of glasdegib 


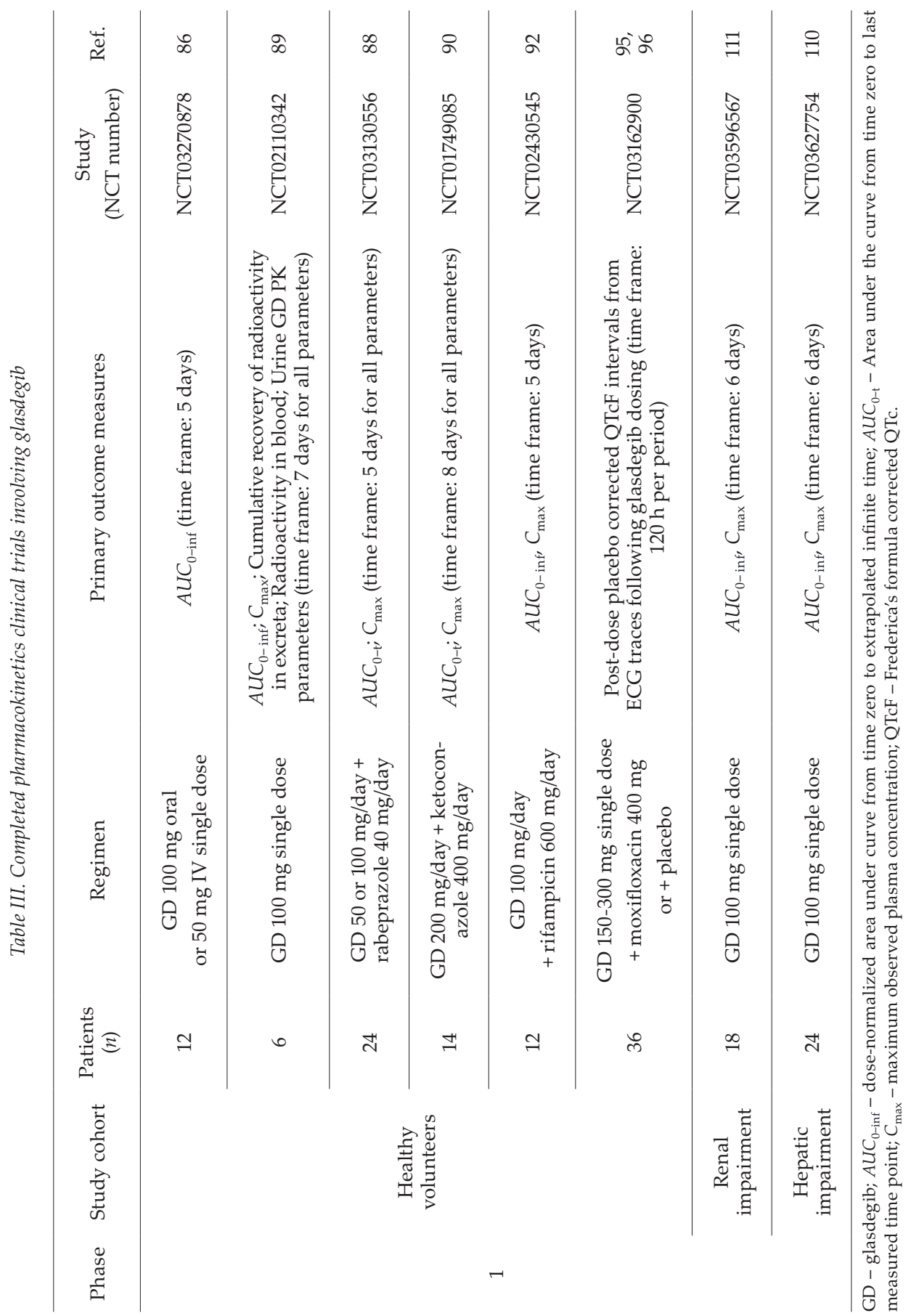


concomitantly with a high-fat, high-calorie meal caused a $13 \%$ lower $A U C_{0 \text {-inf }}$ and $34 \%$ lower $C_{\max }$ compared with glasdegib alone. On the contrary, administration of glasdegib in the presence of ketoconazole resulted in a $140 \%$ higher $A U C_{0 \text {-inf }}$ and $40 \%$ higher $C_{\max }$ compared with glasdegib alone. Whereas the influence of food was not considered clinically meaningful, caution should be used in the case of concomitant administration of strong CYP3A4 inhibitors with glasdegib (91).

The influence of strong CYP3A4 inducers was also explored by the same team in an open-label, fixed sequence, two-period phase I study (NCT02430545, 92). On period 1 (5 days), 12 healthy volunteers received $100 \mathrm{mg}$ oral glasdegib on day 1 . On period 2 (12 days), subjects were administered $600 \mathrm{mg}$ oral rifampicin from day -6 to day 4 and $100 \mathrm{mg}$ glasdegib on day 1 (washout was 11 days between the 2 doses of glasdegib). With rifampicin, a $29.6 \%$ and $64.7 \%$ reduction was observed in $A U C_{0 \text {-inf }}$ and $C_{\max }$ of glasdegib, respectively. Mean half-life decreased from $13.4 \mathrm{~h}$ to $5.1 \mathrm{~h}$ and apparent oral clearance increased from 12.3 to $41.4 \mathrm{~L} \mathrm{~h}^{-1}$. Thus, the association between glasdegib and CYP3A4 inducers should be avoided. If concomitant use can't be avoided, the dose of glasdegib can be doubled and then readjusted 7 days after the inducer is stopped (91).

A summary of clinical trials investigating the pharmacokinetics of glasdegib is provided in Table III.

\section{Safety}

The most commonly observed adverse effects of glasdegib in clinical trials were hematologic disorders (anaemia, febrile neutropenia, thrombocythemia), nausea, decreased appetite, fatigue, muscle spasms, diarrhea and pneumonia $(47,50,51)$. Most of these AEs appeared to be exposure-dependent (93). In the randomized arm of the BRIGHT AML 1003 study (26), grade 3-4 AEs occurred in 64.3 and $56.1 \%$ of patients in the glasdegib + LDAC group and in the LDAC group, respectively. Much rarer events were also observed, such as abnormal Frederica's QTc (in both groups), serious acute kidney injury, serious muscle spasm or elevation of liver enzymes (in combination therapy group). Grade 5 AEs were reported in 28.6 and $41.5 \%$ of patients in these groups, respectively. AEs leading to a dose reduction or temporary treatment interruption were reported in 26.2 and $56.0 \%$ of patients in the glasdegib + LDAC group and in 0 and $31.7 \%$ of patients in the LDAC group. The proportions of serious AEs were relatively similar between the two treatment groups $(78.6 \%$ with combination therapy and $78 \%$ with LDAC alone), moreover, permanent treatment discontinuation were less frequent in glasdegib + LDAC group than in LDAC group (35.7 and $46.3 \%$, respectively). Although glasdegib was associated with significant toxicities, most adverse events were managed with dose interruption or dose modification. In routine clinical practice, a dose modification should be considered in case of G2 muscle-related AE, haematologic toxicity, G3 nonhaematologic AEs or QT interval prolongation (91). In a brief report, Tavares et al. highlighted significant toxicities of glasdegib plus LDAC in compassionate use in 6 high-risk and heavily pretreated AML patients (94). Although this observation was made in a small number of patients, it could suggest a poorer tolerance of this treatment protocol in the salvage setting than in previously untreated patients.

Concerning the influence of glasdegib on QTc interval, Masters et al. led a phase I study (NCT03162900) on 36 healthy volunteers who received a single dose of 150 or $300 \mathrm{mg}$ glasdegib, $400 \mathrm{mg}$ moxifloxacin (positive control) and placebo, according to 4 different 
administration sequences $(95,96)$. None of the subjects reached Frederica's formula corrected QTc (QTcF) interval value $\geq 480 \mathrm{~s}$ or an increased baseline in QTcF interval $\geq 30 \mathrm{~ms}$ after the administration of any treatment (mean differences in QTcF between glasdegib and placebo systematically $<20 \mathrm{~ms}$ ). Thus, although glasdegib had an effect on cardiac repolarization, it was below the $20 \mathrm{~ms}$ threshold of clinical significance usually set in an oncology context $(97,98)$.

Based on its mechanism of action, like other HH pathway inhibitors (99, 100), glasdegib could cause foetal harm and severe birth defects when administered to pregnant women, although there are no clinical data on its impact in this patients population. Its use in women of childbearing potential should therefore be concomitant with an effective contraceptive solution, continued for at least 30 days after the last administration. In males, glasdegib may be present in semen, which can be a source of exposure for female partners with reproductive potential. Because it binds significantly to plasma proteins, the fraction of glasdegib found in milk during breastfeeding is likely to be low; however, no clinical data are available for confirmation (101). In view of the potential adverse effects in breastfed children, breastfeeding is not recommended during treatment with glasdegib and for at least one week after the last dose.

\section{Dosing, administration and counseling points}

Glasdegib is available under the brand-name DAURISMO as oral $25 \mathrm{mg}$ or $100 \mathrm{mg}$ film-coated tablets that may be taken with or without food. Only one tablet should be taken for the recommended dose of $100 \mathrm{mg}$ daily in combination with LDAC (51), whereas the administration of two $25 \mathrm{mg}$ tablets should be considered in case of dosage reduction based on safety and tolerability. A missed dose can be made up unless more than $10 \mathrm{~h}$ have passed since the scheduled administration time. Patients should be encouraged to adhere to a roughly consistent administration schedule each day.

Pharmacists are the leading healthcare professionals in counseling patients about their treatment with glasdegib as they can help prevent and guide the management of AEs associated with this therapy. Concerning the management of common non-haematologic AEs, patients should receive proper counseling on the use of supporting care medications or nonpharmacologic management strategies adapted to the SMOi therapeutic class (102104). The early identification of non-haematologic grade 3 AEs could allow the rapid interruption of treatment until the symptoms diminish or disappear (91). A review of concomitant treatments with glasdegib could also be important to limit the risk of drug-drug interactions, especially with inducers or inhibitors of CYP3A4, QT-prolonging agents or P-glycoprotein substrates (90-92).

\section{Place in therapy}

Although it can occur in patients of any age, AML is mainly a disease of older adults (105). Privileged care for patients with newly diagnosed AML consist of an intensive induction chemotherapy strategy, however, a large proportion of patients is not eligible for these treatments (106). As well as AZA and decitabine, the combination of glasdegib with LDAC is now one of the therapeutic alternatives in older patients and those ineligible for IC (107), particularly because of its notable effectiveness on overall survival compared to 


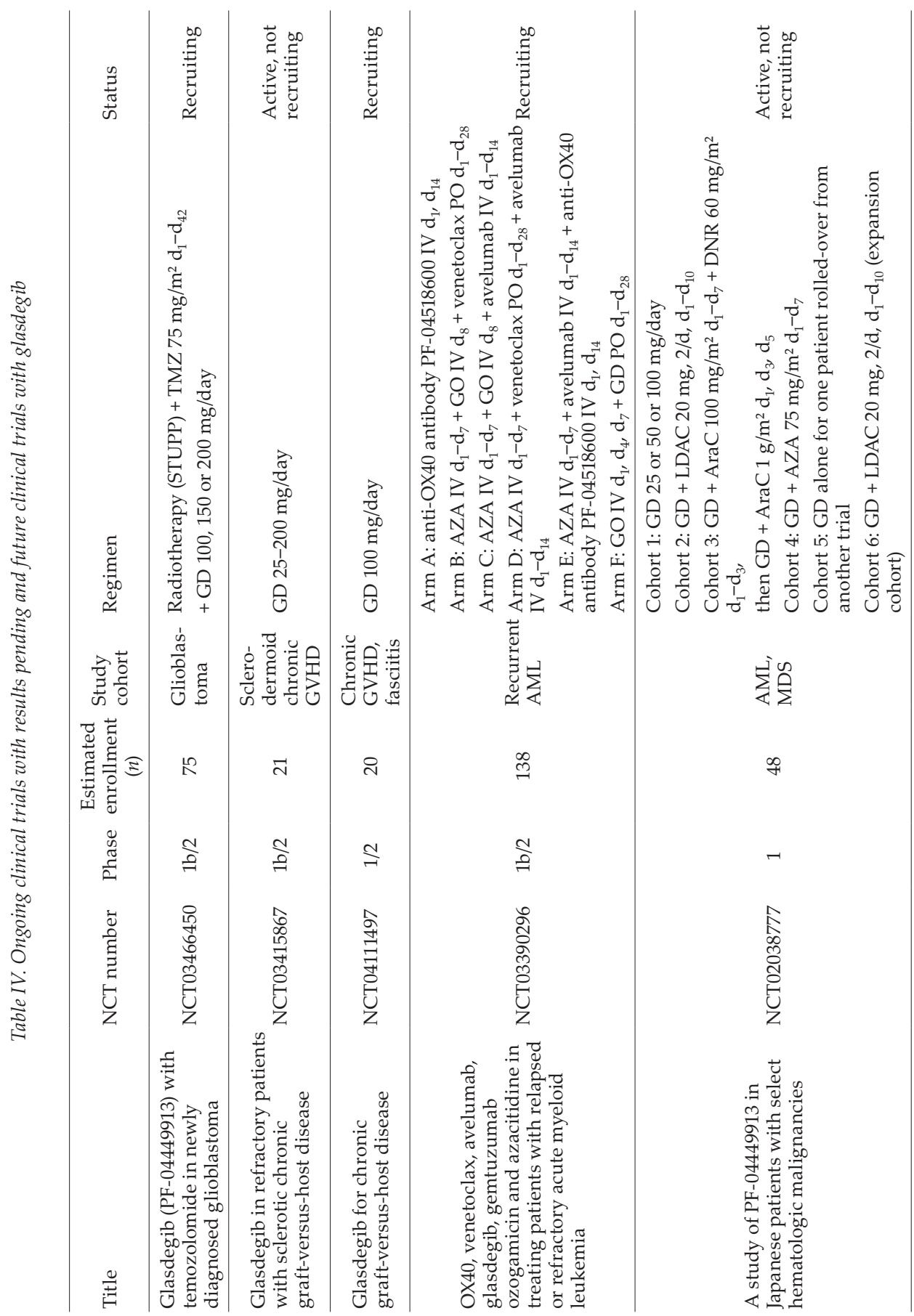




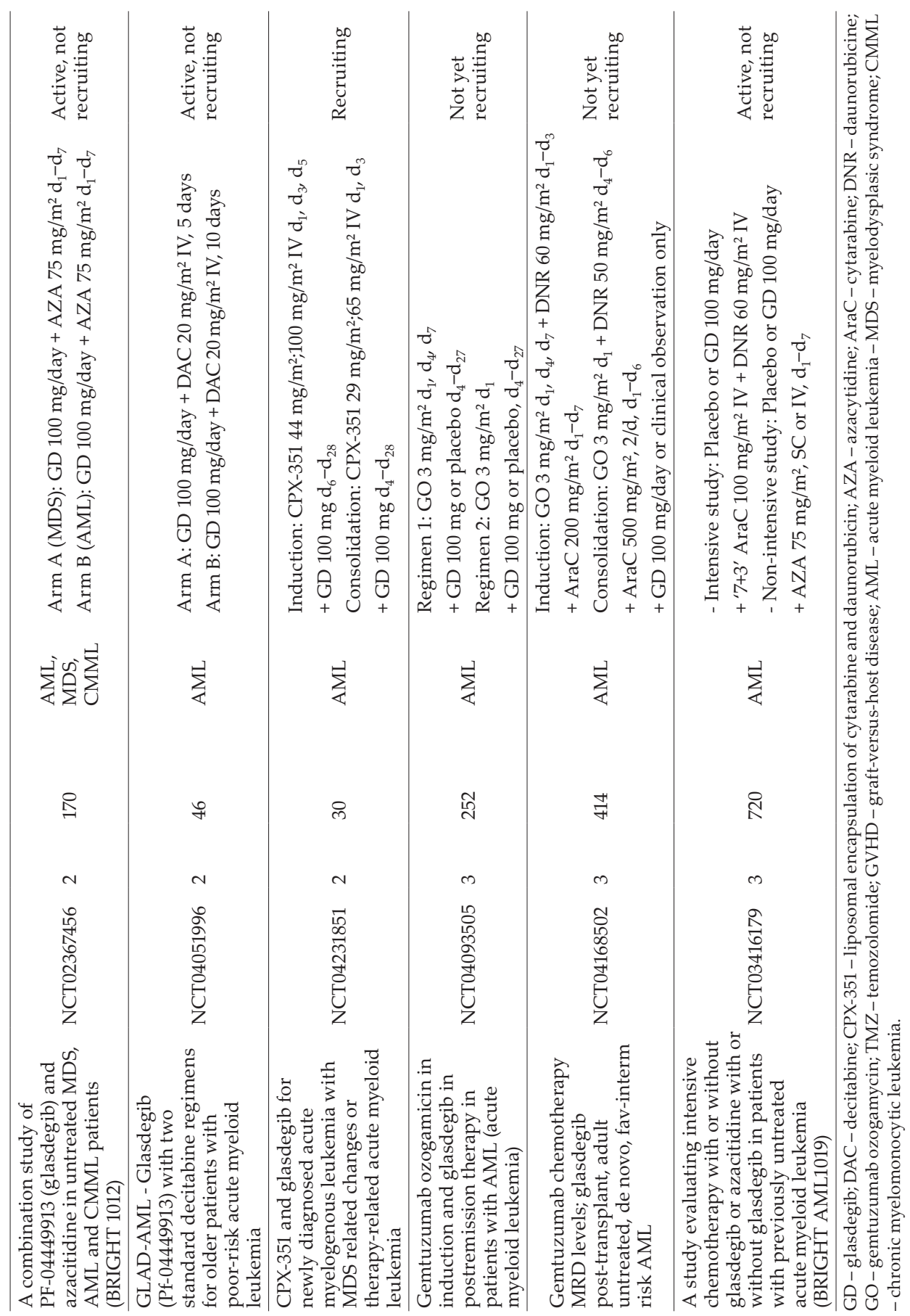


LDAC alone $(26,73)$. In recent years, FDA also approved several new targeted therapies such as gemtuzumab ozogamicin, venetoclax, ivosidenib or midostaurin to treat patients with newly diagnosed AML (108). In this very shifting landscape, the selection of patients best suited for these treatments is an essential questioning. Cortes et al. published expert recommendations suggesting that glasdegib in combination with LDAC could effectively be considered for patients aged $\geq 75$, with poorer risk profiles and prognostic scores, ineligible for IC, with secondary AML or who received prior HMA for MDS (109). Patients with hepatic or renal impairment $(110,111)$ and severe cardiac disease could also benefit from this combination therapy. Despite a monthly list price of 16,925 USD for glasdegib, the budget impact of including glasdegib plus LDAC as first-line treatment from a US health plan perspective was estimated to be low for the US payers, as the eligible patient population size remains small (112).

\section{CONCLUSIONS}

Glasdegib is a recent targeted anticancer agent for the management of AML, particularly in elderly patients not eligible for IC. In combination with LDAC, the use of glasdegib almost doubled the median overall survival compared to LDAC alone in phase II clinical trials that led to the FDA approval of glasdegib (113). Definitive results of the BRIGHT AML 1019 phase III clinical trial, when available, will provide new information on the risk/ benefit profile of glasdegib and on its place in the AML therapeutic strategy in combination with cytotoxic agents such as cytarabine plus daunorubicin (which remain the reference IC regimen for AML patients). Its oral administration route as well as its manageable safety profile could allow better medication adherence and quality of life, especially if a therapeutic education of patients on common AEs is set up. Going forward, several clinical trials involving glasdegib are currently underway (Table IV), investigating its use as monotherapy or in combination with other anticancer agents in both haematological (NCT04231851, NCT04168502, NCT04051996 (114), NCT04655391, NCT04093505, NCT03390296) and solid cancers (NCT03466450).

Acknowledgements. - The authors thank Dr. Emmanuel Deshayes from the Montpellier Cancer Institute for critical comments on this manuscript.

\section{REFERENCES}

1. C. Nüsslein-Volhard and E. Wieschaus, Mutations affecting segment number and polarity in Drosophila, Nature 287 (1980) 795-801; https://doi.org/10.1038/287795a0

2. R. Machold, S. Hayashi, M. Rutlin, M. D. Muzumdar, S. Nery, J. G. Corbin, A. Gritli-Linde, T. Dellovade, J. A. Porter, L. L. Rubin, H. Dudek, A. P. McMahon and G. Fishell, Sonic hedgehog is required for progenitor cell maintenance in telencephalic stem cell niches, Neuron 39 (2003) 937-950; https://doi.org/10.1016/s0896-6273(03)00561-0

3. C. Torroja, N. Gorfinkiel and I. Guerrero, Mechanisms of Hedgehog gradient formation and interpretation, J. Neurobiol. 64 (2005) 334-356; https://doi.org/10.1002/neu.20168

4. M. Varjosalo and J. Taipale, Hedgehog: functions and mechanisms, Genes Dev. 22 (2008) 24542472; https://doi.org/10.1101/gad.1693608 
5. E. Pak and R. A. Segal, Hedgehog signal transduction: Key players, oncogenic drivers, and cancer therapy, Dev. Cell 38 (2016) 333-344; https://doi.org/10.1016/j.devcel.2016.07.026

6. D. M. Stone, M. Hynes, M. Armanini, T. A. Swanson, Q. Gu, R. L. Johnson, M. P. Scott, D. Pennica, A. Goddard, H. Phillips, M. Noll, J. E. Hooper, F. de Sauvage and A. Rosenthal, The tumoursuppressor gene patched encodes a candidate receptor for Sonic hedgehog, Nature 384 (1996) 129-134; https://doi.org/10.1038/384129a0

7. M. Kasper, H. Schnidar, G. W. Neill, M. Hanneder, S. Klingler, L. Blaas, C. Schmid, C. Hauser-Kronberger, G. Regl, M. P. Philpott and F. Aberger, Selective modulation of Hedgehog/GLI target gene expression by epidermal growth factor signaling in human keratinocytes, Mol. Cell. Biol. 26 (2006) 6283-6298; https://doi.org/10.1128/MCB.02317-05

8. I. D. Louro, E. C. Bailey, X. Li, L. S. South, P. R. McKie-Bell, B. K. Yoder, C. C. Huang, M. R. Johnson, A. E. Hill, R. L. Johnson and J. M. Ruppert, Comparative gene expression profile analysis of GLI and c-MYC in an epithelial model of malignant transformation, Cancer Res. 62 (2002) 5867-5873.

9. L. E. C. Wanshura, K. E. Galvin, H. Ye, M. E. Fernandez-Zapico and C. Wetmore, Sequential activation of Snail1 and N-Myc modulates Sonic Hedgehog-induced transformation of neural cells, Cancer Res. 71 (2011) 5336-5345; https://doi.org/10.1158/0008-5472.CAN-10-2633

10. M. Merchant, F. F. Vajdos, M. Ultsch, H. R. Maun, U. Wendt, J. Cannon, W. Desmarais, R. A. Lazarus, A. M. de Vos and F. J. de Sauvage, Suppressor of Fused regulates Gli activity through a dual binding mechanism, Mol. Cell. Biol. 24 (2004) 8627-8641; https://doi.org/10.1128/MCB.24.19.86278641.2004

11. A. M. Skoda, D. Simovic, V. Karin, V. Kardum, S. Vranic and L. Serman, The role of the Hedgehog signaling pathway in cancer: A comprehensive review, Bosn. J. Basic Med. Sci. 18 (2018) 8-20; https://doi.org/10.17305/bjbms.2018.2756

12. C. Zhao, A. Chen, C. H. Jamieson, M. Fereshteh, A. Abrahamsson, J. Blum, H. Y. Kwon, J. Kim, J. P. Chute, D. Rizzieri, M. Munchhof, T. VanArsdale, P. A. Beachy and T. Reya, Hedgehog signalling is essential for maintenance of cancer stem cells in myeloid leukaemia, Nature 458 (2009) 776-779; https://doi.org/10.1038/nature07737

13. N. Bhagwat, M. D. Keller, R. K. Rampal, K. Shank, E. de Stanchina, K. Rose, D. Amakye and R. L. Levine, Improved efficacy of combination of JAK2 and Hedgehog inhibitors in myelofibrosis, Blood 122 (2013) 666-666; https://doi.org/10.1182/blood.V122.21.666.666

14. J. M. Xavier-Ferrucio, F. V. Pericole, M. R. Lopes, P. Latuf-Filho, K. S. A. Barcellos, A. I. Dias, P. de M. Campos, F. Traina, J. Vassallo, S. T. O. Saad and P. Favaro, Abnormal Hedgehog pathway in myelodysplastic syndrome and its impact on patients' outcome, Haematologica 100 (2015) e491-493; https://doi.org/10.3324/haematol.2015.124040

15. M. Kobune, R. Takimoto, K. Murase, S. Iyama, T. Sato, S. Kikuchi, Y. Kawano, K. Miyanishi, Y. Sato, Y. Niitsu and J. Kato, Drug resistance is dramatically restored by hedgehog inhibitors in CD34+ leukemic cells, Cancer Sci. 100 (2009) 948-955; https://doi.org/10.1111/j.1349-7006.2009.01111.x

16. B. Long, L.-X. Wang, F.-M. Zheng, S.-P. Lai, D.-R. Xu, Y. Hu, D.-J. Lin, X.-Z. Zhang, L. Dong, Z.-J. Long, X.-Z. Tong and Q. Liu, Targeting GLI1 suppresses cell growth and enhances chemosensitivity in CD34+ enriched acute myeloid leukemia progenitor cells, Cell. Physiol. Biochem. Int. J. Exp. Cell. Physiol. Biochem. Pharmacol. 38 (2016) 1288-1302; https://doi.org/10.1159/000443075

17. K. C. S. Queiroz, R. R. Ruela-de-Sousa, G. M. Fuhler, H. L. Aberson, C. V. Ferreira, M. P. Peppelenbosch and C. A. Spek, Hedgehog signaling maintains chemoresistance in myeloid leukemic cells, Oncogene 29 (2010) 6314-6322; https://doi.org/10.1038/onc.2010.375

18. H. A. Zahreddine, B. Culjkovic-Kraljacic, S. Assouline, P. Gendron, A. A. Romeo, S. J. Morris, G. Cormack, J. B. Jaquith, L. Cerchietti, E. Cocolakis, A. Amri, J. Bergeron, B. Leber, M. W. Becker, S. Pei, C. T. Jordan, W. H. Miller and K. L. B. Borden, The sonic hedgehog factor GLI1 imparts drug resistance through inducible glucuronidation, Nature 511 (2014) 90-93; https://doi.org/10.1038/nature13283 
19. K. Huang, B. Ding, Q. Zhong, X. Jiang, X. Li, Z. Wang and F. Y. Meng, Hh/IGF-1R/PI3K/Akt/MRP1 pathway induce refractory acute myeloid leukemia and its targeting therapy, Blood 124 (2014) 3612-3612; https://doi.org/10.1182/blood.V124.21.3612.3612

20. F. Meng, X. Li, B. Ding, K. Huang, Q. Zhu, F. Chen and Y. Zhu, Molecular mechanism and optimal treatment strategy in acute myeloid leukemia with resistance to drugs and radiation by NVPLED225, Blood 126 (2015) 3691-3691; https://doi.org/10.1182/blood.V126.23.3691.3691

21. X. Li, F. Chen, Q. Zhu, B. Ding, Q. Zhong, K. Huang, X. Jiang, Z. Wang, C. Yin, Y. Zhu, Z. Li and F. Meng, Gli-1/PI3K/AKT/NF-kB pathway mediates resistance to radiation and is a target for reversion of responses in refractory acute myeloid leukemia cells, Oncotarget 7 (2016) 33004-33015; https://doi.org/10.18632/oncotarget.8844

22. J. Bariwal, V. Kumar, Y. Dong and R. I. Mahato, Design of Hedgehog pathway inhibitors for cancer treatment, Med. Res. Rev. 39 (2019) 1137-1204; https://doi.org/10.1002/med.21555

23. R. Tibes, A. Al-Kali, G. R. Oliver, D. H. Delman, N. Hansen, K. Bhagavatula, J. Mohan, F. Rakhshan, T. Wood, J. M. Foran, R. A. Mesa and J. M. Bogenberger, The Hedgehog pathway as targetable vulnerability with 5-azacytidine in myelodysplastic syndrome and acute myeloid leukemia, J. Hematol. Oncol. 8 (2015) 114; https://doi.org/10.1186/s13045-015-0211-8

24. D. A. Irvine, B. Zhang, R. Kinstrie, A. Tarafdar, H. Morrison, V. L. Campbell, H. A. Moka, Y. Ho, C. Nixon, P. W. Manley, H. Wheadon, J. R. Goodlad, T. L. Holyoake, R. Bhatia and M. Copland, Deregulated Hedgehog pathway signaling is inhibited by the smoothened antagonist LDE225 (Sonidegib) in chronic phase chronic myeloid leukaemia, Sci. Rep. 6 (2016) 25476; https://doi. org/10.1038/srep25476

25. J. E. Cortes, R. Gutzmer, M. W. Kieran and J. A. Solomon, Hedgehog signaling inhibitors in solid and hematological cancers, Cancer Treat. Rev. 76 (2019) 41-50; https://doi.org/10.1016/j. ctrv.2019.04.005

26. J. E. Cortes, F. H. Heidel, A. Hellmann, W. Fiedler, B. D. Smith, T. Robak, P. Montesinos, D. A. Pollyea, P. DesJardins, O. Ottmann, W. W. Ma, M. N. Shaik, A. D. Laird, M. Zeremski, A. O'Connell, G. Chan and M. Heuser, Randomized comparison of low dose cytarabine with or without glasdegib in patients with newly diagnosed acute myeloid leukemia or high-risk myelodysplastic syndrome, Leukemia 33 (2019) 379-389; https://doi.org/10.1038/s41375-018-0312-9

27. S. M. Hoy, Glasdegib: First global approval, Drugs 79 (2019) 207-213; https://doi.org/10.1007/s40265018-1047-7

28. K. J. Norsworthy, K. By, S. Subramaniam, L. Zhuang, P. L. Del Valle, D. Przepiorka, Y.-L. Shen, C. M. Sheth, C. Liu, R. Leong, K. B. Goldberg, A. T. Farrell and R. Pazdur, FDA approval summary: glasdegib for newly diagnosed acute myeloid leukemia, Clin. Cancer Res. 25 (2019) 6021-6025; https://doi.org/10.1158/1078-0432.CCR-19-0365

29. E. Estey, J. E. Karp, A. Emadi, M. Othus and R. P. Gale, Recent drug approvals for newly diagnosed acute myeloid leukemia: gifts or a Trojan horse?, Leukemia 34 (2020) 671-681; https://doi.org/10.1038/ s41375-019-0704-5

30. T. Hilal, Progress in acute myeloid leukaemia: small molecular inhibitors with small benefits, Ecancermedicalscience 14 (2020); https://doi.org/10.3332/ecancer.2020.1015

31. A. Fiorentini, D. Capelli, F. Saraceni, D. Menotti, A. Poloni and A. Olivieri, The time has come for targeted therapies for AML: lights and shadows, Oncol. Ther. 8 (2020) 13-32; https://doi.org/10.1007/ s40487-019-00108-x

32. M. J. Munchhof, Q. Li, A. Shavnya, G. V. Borzillo, T. L. Boyden, C. S. Jones, S. D. LaGreca, L. Martinez-Alsina, N. Patel, K. Pelletier, L. A. Reiter, M. D. Robbins and G. T. Tkalcevic, Discovery of PF-04449913, a potent and orally bioavailable inhibitor of Smoothened, ACS Med. Chem. Lett. 3 (2012) 106-111; https://doi.org/10.1021/ml2002423 
33. L. Rubin, O. M. Guicherit, S. Price and E. A. Boyd, Mediators of Hedgehog signaling pathways, compositions and uses related thereto; Retrieved from https://patents.google.com/patent/ WO2003011219A2/en

34. A. J. Jackson-Fisher, M. J. McMahon, J. Lam, C. Li, L. D. Engstrom, K. Tsaparikos, D. J. Shields, D. D. Fang, M. E. Lira, Z. Zhu, M. D. Robbins, R. Schwab, M. J. Munchhof and T. VanArsdale, Abstract 4504: PF-04449913, a small molecule inhibitor of Hedgehog signaling, is effective in inhibiting tumor growth in preclinical models, Exp. Mol. Ther. (pp. 4504-4504). Presented at the Proceedings: AACR 102nd Annual Meeting 2011 - Apr 2-6, 2011; Orlando, FL, American Association for Cancer Research; https://doi.org/10.1158/1538-7445.AM2011-4504

35. G. Martinelli, V. G. Oehler, C. Papayannidis, R. Courtney, M. N. Shaik, X. Zhang, A. O'Connell, K. R. McLachlan, X. Zheng, J. Radich, M. Baccarani, H. M. Kantarjian, W. J. Levin, J. E. Cortes and C. Jamieson, Treatment with PF-04449913, an oral Smoothened antagonist, in patients with myeloid malignancies: a phase 1 safety and pharmacokinetics study, Lancet Haematol. 2 (2015) e339346; https://doi.org/10.1016/S2352-3026(15)00096-4

36. A. J. Wagner, W. A. Messersmith, M. N. Shaik, S. Li, X. Zheng, K. R. McLachlan, R. Cesari, R. Courtney, W. J. Levin and A. B. El-Khoueiry, A phase I study of PF-04449913, an oral Hedgehog inhibitor, in patients with advanced solid tumors, Clin. Cancer Res. 21 (2015) 1044-1051; https://doi. org/10.1158/1078-0432.CCR-14-1116

37. G. Giordani, M. Barraco, A. Giangrande, G. Martinelli, V. Guadagnuolo, G. Simonetti, G. Perini and R. Bernardoni, The human Smoothened inhibitor PF-04449913 induces exit from quiescence and loss of multipotent Drosophila hematopoietic progenitor cells, Oncotarget 7 (2016) 55313-55327; https://doi.org/10.18632/oncotarget.10879

38. M. Copland, A. Hamilton, L. J. Elrick, J. W. Baird, E. K. Allan, N. Jordanides, M. Barow, J. C. Mountford and T. L. Holyoake, Dasatinib (BMS-354825) targets an earlier progenitor population than imatinib in primary CML but does not eliminate the quiescent fraction, Blood 107 (2006) 4532-4539; https://doi.org/10.1182/blood-2005-07-2947

39. X. Jiang, Y. Zhao, C. Smith, M. Gasparetto, A. Turhan, A. Eaves and C. Eaves, Chronic myeloid leukemia stem cells possess multiple unique features of resistance to BCR-ABL targeted therapies, Leukemia 21 (2007) 926-935; https://doi.org/10.1038/sj.leu.2404609

40. C. Dierks, R. Beigi, G.-R. Guo, K. Zirlik, M. R. Stegert, P. Manley, C. Trussell, A. Schmitt-Graeff, K. Landwerlin, H. Veelken and M. Warmuth, Expansion of Bcr-Abl-positive leukemic stem cells is dependent on Hedgehog pathway activation, Cancer Cell 14 (2008) 238-249; https://doi.org/10.1016/j. ccr.2008.08.003

41. N. Fukushima, Y. Minami, S. Kakiuchi, Y. Kuwatsuka, F. Hayakawa, C. Jamieson, H. Kiyoi and T. Naoe, Small-molecule Hedgehog inhibitor attenuates the leukemia-initiation potential of acute myeloid leukemia cells, Cancer Sci. 107 (2016) 1422-1429; https://doi.org/10.1111/cas.13019

42. A. Schairer, A. Shih, I. Geron, T. Reya, W. J. Levin, T. Van Arsdale and C. Jamieson, Human blast crisis leukemia stem cell inhibition with a novel Smoothened antagonist., Blood 116 (2010) 12231223; https://doi.org/10.1182/blood.V116.21.1223.1223

43. A. Y. Shih, A. Schairer, C. L. Barrett, I. Geron, A. C. Court Recart, D. Goff, S. Prashad, J. Wu, Q. Jiang, J. Gotlib, L. Balaian, M. D. Minden, H. Leu, R. Wall, W. Ma, K. Shazand, J. D. McPherson, S. M. Kornblau, I. Deichaite, M. Pu, L. Bao, G. Martinelli, T. Reya, S. R. Morris, T. van Arsdale, T. J. Hudson, K. Messer, H. Mikkola, W. J. Levin, K. A. Frazer, A. Sadarangani and C. Jamieson, Cycling toward leukemia stem cell elimination with a selective Sonic Hedgehog antagonist, Blood 118 (2011) 3776-3776; https://doi.org/10.1182/blood.V118.21.3776.3776

44. P. Chaudhry, M. Singh, T. J. Triche, M. Guzman and A. A. Merchant, GLI3 repressor determines Hedgehog pathway activation and is required for response to SMO antagonist glasdegib in AML, Blood 129 (2017) 3465-3475; https://doi.org/10.1182/blood-2016-05-718585 
45. A. Jackson-Fisher, P. Whalen, M. Elliott, M. McMahon, E. Chen, X. Zheng, M. Ozeck, D. Huang, P. Lira, J. Lee, C. Zhang, J. Lam, M. Spilker, S. Deng, P. Lappin, P. Venne, C. Heinlein, A. Schairer, K. McLachlan and T. VanArsdale, Abstract 1958: Interrogating Hedgehog pathway and smoothened inhibition by PF-04449913 in patient-derived acute myeloid leukemia models, Tumor Biol. (pp. 1958-1958). Presented at the Proceedings: AACR Annual Meeting 2014; April 5-9, 2014; San Diego, CA, American Association for Cancer Research; https://doi.org/10.1158/1538-7445.AM2014-1958

46. A. Sadarangani, G. Pineda, K. M. Lennon, H.-J. Chun, A. Shih, A. E. Schairer, A. C. Court, D. J. Goff, S. L. Prashad, I. Geron, R. Wall, J. D. McPherson, R. A. Moore, M. Pu, L. Bao, A. JacksonFisher, M. Munchhof, T. VanArsdale, T. Reya, S. R. Morris, M. D. Minden, K. Messer, H. K. A. Mikkola, M. A. Marra, T. J. Hudson and C. H. M. Jamieson, GLI2 inhibition abrogates human leukemia stem cell dormancy, J. Transl. Med. 13 (2015) 98; https://doi.org/10.1186/s12967-015-0453-9

47. C. Jamieson, J. E. Cortes, V. Oehler, M. Baccarani, H. M. Kantarjian, C. Papayannidis, K. N. Rice, X. Zhang, N. Shaik, R. Courtney, W. J. Levin and G. Martinelli, Phase 1 Dose-escalation study of PF-04449913, an oral Hedgehog (Hh) inhibitor, in patients with select hematologic malignancies, Blood 118 (2011) 424-424; https://doi.org/10.1182/blood.V118.21.424.424

48. V. Guadagnuolo, C. Papayannidis, I. Iacobucci, S. Durante, C. Terragna, E. Ottaviani, M. C. Abbenante, F. Cattina, S. Soverini, B. Lama, L. Toni, W. J. Levin, R. Courtney, C. Baldazzi, A. Curti, M. Baccarani, C. Jamieson, J. E. Cortes, V. Oehler, K. McLachlan, T. Van Arsdale and G. Martinelli, Gas1 and Kif27 genes are strongly up-regulated biomarkers of Hedgehog inhibition (PF04449913) on leukemia stem cells in phase I acute myeloid leukemia and chronic myeloid leukemia treated patients, Blood 118 (2011) 1535-1535; https://doi.org/10.1182/blood.V118.21.1535.1535

49. C. Papayannidis, V. Guadagnuolo, I. Iacobucci, S. Durante, C. Terragna, E. Ottaviani, M. C. Abbenante, F. Cattina, S. Soverini, B. Lama, L. Toni, W. J. Levin, R. Courtney, C. Baldazzi, A. Curti, M. Baccarani, C. Jamieson, J. E. Cortes, V. Oehler, K. McLachlan, T. Van Arsdale and G. Martinelli, PF-04449913 reverts multi drug resistance (MDR) by a strong down-regulation of ABCA2 and BCL2 on leukemia stem cells in phase I acute myeloid leukemia and chronic myeloid leukemia treated patients, Blood 118 (2011) 1429-1429; https://doi.org/10.1182/blood.V118.21.1429.1429

50. Y. Minami, H. Minami, T. Miyamoto, G. Yoshimoto, Y. Kobayashi, W. Munakata, Y. Onishi, M. Kobayashi, M. Ikuta, G. Chan, A. Woolfson, C. Ono, M. N. Shaik, Y. Fujii, X. Zheng and T. Naoe, Phase I study of glasdegib (PF-04449913), an oral Smoothened inhibitor, in Japanese patients with select hematologic malignancies, Cancer Sci. 108 (2017) 1628-1633; https://doi.org/10.1111/cas.13285

51. M. R. Savona, D. A. Pollyea, W. Stock, V. G. Oehler, M. A. Schroeder, J. Lancet, J. McCloskey, H. M. Kantarjian, W. W. Ma, M. N. Shaik, A. D. Laird, M. Zeremski, A. O'Connell, G. Chan and J. E. Cortes, Phase Ib study of glasdegib, a Hedgehog pathway inhibitor, in combination with standard chemotherapy in patients with AML or high-risk MDS, Clin. Cancer Res. 24 (2018) 2294-2303; https://doi.org/10.1158/1078-0432.CCR-17-2824

52. U. Borate, B. D. Smith, S. Gore, A. M. Zeidan, M. R. Savona, M. L. Savoie, N. Zhu, D. Breems, X. Zhang, M. N. Shaik, A. Rampersad, G. Chan, A. Woolfson and M. A. Sekeres, Phase 1B study of glasdegib (PF-04449913) in combination with azacitidine in patients with higher risk myelodysplasic syndrome, oligoblastic acute myeloid leukemia, or chronic myelomonocytic leukemia [abstract no. P255], Haematologica 101 (Suppl 1) (2016) 73-74.

53. M. A. Sekeres, M. W. Schuster, M. Joris, J. Krauter, J. A. Maertens, E. Gyan, T. Kovacsovics, A. Verma, P. Vyas, E. S. Wang, W. Wendy Ma, M. Zeremski, A. Kudla, G. Chan and A. M. Zeidan, A phase $1 \mathrm{~b}$ study of glasdegib in combination with azacitidine in patients with untreated higherrisk myelodysplastic syndromes, acute myeloid leukemia, and chronic myelomonocytic leukemia, Blood 134 (2019) 177-177; https://doi.org/10.1182/blood-2019-124050

54. A. M. Zeidan, M. Schuster, M. Joris, J. Krauter, J. Maertens, E. Gyan, T. Kovacsovics, A. Verma, P. Vyas, E. S. Wang, W. Ma, M. Zeremski, A. Kudla, G. Chan and M. A. Sekeres, Glasdegib in combination with azacitidine (AZA) in patients (pts) with untreated higher-risk myelodysplastic syndromes (MDS), acute myeloid leukemia (AML) and chronic myelomonocytic leukemia (CMML): 
Effects on marrow recovery and transfusion independence, J. Clin. Oncol. 38 (2020) 7526-7526; https://doi.org/10.1200/JCO.2020.38.15_suppl.7526

55. E. S. Wang, T. Bell, A. M. Zeidan, H. Bhattacharyya, A. Kudla, G. Chan and M. A. Sekeres, Healthrelated quality of life (HRQoL) in patients with untreated higher-risk myelodysplastic syndromes (MDS), acute myeloid leukemia (AML), and chronic myelomonocytic leukemia (CMML) receiving glasdegib + azacitidine (AZA), J. Clin. Oncol. 38 (2020) 7527-7527; https://doi.org/10.1200/ JCO.2020.38.15_suppl.7527

56. A. T. Gerds, T. Tauchi, E. Ritchie, M. Deininger, C. Jamieson, R. Mesa, M. Heaney, N. Komatsu, H. Minami, Y. Su, N. Shaik, X. Zhang, C. DiRienzo, M. Zeremski, G. Chan and M. Talpaz, Phase 1/2 trial of glasdegib in patients with primary or secondary myelofibrosis previously treated with ruxolitinib, Leuk. Res. 79 (2019) 38-44; https://doi.org/10.1016/j.leukres.2019.02.012

57. J. E. Cortes, B. Douglas Smith, E. S. Wang, A. Merchant, V. G. Oehler, M. Arellano, D. J. DeAngelo, D. A. Pollyea, M. A. Sekeres, T. Robak, W. W. Ma, M. Zeremski, M. Naveed Shaik, A. Douglas Laird, A. O'Connell, G. Chan and M. A. Schroeder, Glasdegib in combination with cytarabine and daunorubicin in patients with AML or high-risk MDS: Phase 2 study results, Am. J. Hematol. 93 (2018) 1301-1310; https://doi.org/10.1002/ajh.25238

58. H. Kantarjian, Y. Oki, G. Garcia-Manero, X. Huang, S. O’Brien, J. Cortes, S. Faderl, C. Bueso-Ramos, F. Ravandi, Z. Estrov, A. Ferrajoli, W. Wierda, J. Shan, J. Davis, F. Giles, H. I. Saba and J.-P. J. Issa, Results of a randomized study of 3 schedules of low-dose decitabine in higher-risk myelodysplastic syndrome and chronic myelomonocytic leukemia, Blood 109 (2007) 52-57; https://doi. org/10.1182/blood-2006-05-021162

59. S. Thépot, R. Itzykson, V. Seegers, C. Recher, E. Raffoux, B. Quesnel, J. Delaunay, T. Cluzeau, A. Marfaing Koka, A. Stamatoullas, M.-P. Chaury, C. Dartigeas, S. Cheze, A. Banos, P. Morel, I. Plantier, A.-L. Taksin, J. P. Marolleau, C. Pautas, X. Thomas, F. Isnard, B. Beve, Y. Chait, A. Guerci, N. Vey, F. Dreyfus, L. Ades, N. Ifrah, H. Dombret, P. Fenaux and C. Gardin, Azacitidine in untreated acute myeloid leukemia: a report on 149 patients: azacitidine in frontline AML, Am. J. Hematol. 89 (2014) 410-416; https://doi.org/10.1002/ajh.23654

60. H. Dombret, J. F. Seymour, A. Butrym, A. Wierzbowska, D. Selleslag, J. H. Jang, R. Kumar, J. Cavenagh, A. C. Schuh, A. Candoni, C. Récher, I. Sandhu, T. Bernal del Castillo, H. K. Al-Ali, G. Martinelli, J. Falantes, R. Noppeney, R. M. Stone, M. D. Minden, H. McIntyre, S. Songer, L. M. Lucy, C. L. Beach and H. Döhner, International phase 3 study of azacitidine vs conventional care regimens in older patients with newly diagnosed AML with >30\% blasts, Blood 126 (2015) 291-299; https://doi.org/10.1182/blood-2015-01-621664

61. S. M. Luger, Acute myeloid leukemia: how to treat the fit patient over age 75?, Best Pract. Res. Clin. Haematol. 32 (2019) 101105; https://doi.org/10.1016/j.beha.2019.101105

62. J. E. Cortes, A. Merchant, C. Jamieson, D. A. Pollyea, M. Heuser, G. Chan, P. Wang, K. A. Ching, J. Johnson and T. O'Brien, Biomarkers of overall survival and response to glasdegib and intensive or non-intensive chemotherapy in patients with acute myeloid leukemia, Blood 132 (2018) 1429_ 1429; https://doi.org/10.1182/blood-2018-99-111239

63. K. A. Ching, D. Huang, K. Wang, M. Ozeck, P. Lira, J. Gao, J. Bienkowska, P. Rejto, J. Hardwick, T. $\mathrm{O}$ 'Brien and G. Chan, Analysis of mutations associated with response to glasdegib in acute myeloid leukemia (AML) and myelodysplastic syndrome (MDS), Clin. Res. Clin. Trials (pp. LB-215LB-215). Presented at the Proceedings: AACR Annual Meeting 2018; April 14-18, 2018; Chicago, IL, American Association for Cancer Research.; https://doi.org/10.1158/1538-7445.AM2018-LB-215

64. S. Lin, N. Shaik, G. Chan, J. E. Cortes and A. Ruiz-Garcia, An evaluation of overall survival in patients with newly diagnosed acute myeloid leukemia and the relationship with glasdegib treatment and exposure, Cancer Chemother. Pharmacol. 86 (2020) 451-459; https://doi.org/10.1007/s00280020-04132-x 
65. H. Döhner, M. Lübbert, W. Fiedler, L. Fouillard, A. Haaland, J. M. Brandwein, S. Lepretre, O. Reman, P. Turlure, O. G. Ottmann, C. Müller-Tidow, A. Krämer, E. Raffoux, K. Döhner, R. F. Schlenk, F. Voss, T. Taube, H. Fritsch and J. Maertens, Randomized, phase 2 trial of low-dose cytarabine with or without volasertib in AML patients not suitable for induction therapy, Blood 124 (2014) 1426-1433.; https://doi.org/10.1182/blood-2014-03-560557

66. A. K. Burnett, N. Russell, R. K. Hills, N. Panoskaltsis, A. Khwaja, C. Hemmaway, P. Cahalin, R. E. Clark and D. Milligan, A randomised comparison of the novel nucleoside analogue sapacitabine with low-dose cytarabine in older patients with acute myeloid leukaemia, Leukemia 29 (2015) 1312-1319; https://doi.org/10.1038/leu.2015.38

67. M. Heiblig, M. Elhamri, I. Tigaud, A. Plesa, F. Barraco, H. Labussière, S. Ducastelle, M. Michallet, F. Nicolini, C. Plesa, E. Wattel, G. Salles and X. Thomas, Treatment with low-dose cytarabine in elderly patients (age 70 years or older) with acute myeloid leukemia: a single institution experience, Mediterr. J. Hematol. Infect. Dis. 8 (2016) 2016009; https://doi.org/10.4084/mjhid.2016.009

68. A. T. Fathi, Glasdegib with low-dose cytarabine: a new upfront option for the vulnerable AML patient, Clin. Cancer Res. 25 (2019) 6015-6017; https://doi.org/10.1158/1078-0432.CCR-19-1986

69. C. Papayannidis, B. D. Smith, M. Heuser, P. Montesinos, M. A. Sekeres, A. Oriol, G. Schiller, A. Candoni, C. Jamieson, C. J. Hoang, W. W. Ma, M. Zeremski, A. O'Connell, G. Chan and J. E. Cortes, Low-dose cytarabine with or without glasdegib in newly diagnosed patients with acute myeloid leukemia: long-term analysis of a phase 2 randomized trial, Clin. Lymphoma Myeloma Leuk. 19 (2019) S228-S229; https://doi.org/10.1016/j.clml.2019.07.111

70. M. Heuser, W. Fiedler, M. A. Sekeres, P. Montesinos, B. Leber, A. Merchant, C. Papayannidis, J. A. Pérez-Simón, C. J. Hoang, W. Wendy Ma, M. Zeremski, A. O’Connell, G. Chan and J. E. Cortes, Clinical benefit of glasdegib plus low-dose cytarabine in patients with de novo and secondary acute myeloid leukemia: long-term analysis of a phase 2 randomized trial, Clin. Lymphoma Myeloma Leuk. 19 (2019) S231-S231; https://doi.org/10.1016/j.clml.2019.07.116

71. C. D. DiNardo, K. W. Pratz, A. Letai, B. A. Jonas, A. H. Wei, M. Thirman, M. Arellano, M. G. Frattini, H. Kantarjian, R. Popovic, B. Chyla, T. Xu, M. Dunbar, S. K. Agarwal, R. Humerickhouse, M. Mabry, J. Potluri, M. Konopleva and D. A. Pollyea, Safety and preliminary efficacy of venetoclax with decitabine or azacitidine in elderly patients with previously untreated acute myeloid leukaemia: a non-randomised, open-label, phase 1b study, Lancet Oncol. 19 (2018) 216-228; https://doi. org/10.1016/S1470-2045(18)30010-X

72. A. Wolska-Washer and T. Robak, Glasdegib in the treatment of acute myeloid leukemia, Future Oncol. Lond. Engl. 15 (2019) 3219-3232; https://doi.org/10.2217/fon-2019-0171

73. M. Heuser, T. Robak, P. Montesinos, B. Leber, W. M. Fiedler, D. A. Pollyea, A. Brown, A. O'Connell, W. Ma, G. Chan and J. E. Cortes, Glasdegib (GLAS) plus low-dose cytarabine (LDAC) in AML or MDS: BRIGHT AML 1003 final report and four-year overall survival (OS) follow-up, J. Clin. Oncol. 38 (2020) 7509-7509; https://doi.org/10.1200/JCO.2020.38.15_suppl.7509

74. J. E. Cortes, F. H. Heidel, W. Fiedler, B. D. Smith, T. Robak, P. Montesinos, A. Candoni, B. Leber, M. A. Sekeres, D. A. Pollyea, R. Ferdinand, W. W. Ma, T. O'Brien, A. O'Connell, G. Chan and M. Heuser, Survival outcomes and clinical benefit in patients with acute myeloid leukemia treated with glasdegib and low-dose cytarabine according to response to therapy, J. Hematol. Oncol. 13 (2020) 92; https://doi.org/10.1186/s13045-020-00929-8

75. E. S. Wang, M. Heuser, M. A. Sekeres, C. Papayannidis, A. Candoni, A. Merchant, A. Brown, A. O'Connell, W. Ma, G. Chan and J. E. Cortes, Effect of early blood counts on overall survival (OS) following glasdegib + LDAC in newly diagnosed AML: BRIGHT AML 1003 post hoc analysis, J. Clin. Oncol. 38 (2020) 7525-7525; https://doi.org/10.1200/JCO.2020.38.15_suppl.7525

76. G. Tremblay, T. Westley, J. C. Cappelleri, B. Arondekar, G. Chan, T. J. Bell and A. Briggs, Overall survival of glasdegib in combination with low-dose cytarabine, azacitidine, and decitabine among adult patients with previously untreated AML: comparative effectiveness using simulated 
treatment comparisons, Clin. Outcomes Res. CEOR 11 (2019) 551-565; https://doi.org/10.2147/CEOR. S203482

77. S. van Beekhuizen, Y. Hu, A. Gezin, B. Heeg, T. Bell, M. Charaan, A. Brown, G. Chan and J. C. Cappelleri, The comparative effectiveness of glasdegib in combination with low-dose cytarabine versus azacitidine by bone marrow blasts counts among patients with newly-diagnosed acute myeloid leukemia who are ineligible for intensive chemotherapy, J. Clin. Oncol. 38 (2020) e19512e19512; https://doi.org/10.1200/JCO.2020.38.15_suppl.e19512

78. J. E. Lancet, R. S. Komrokji, K. L. Sweet, V. H. Duong, K. L. McGraw, L. Zhang, L. A. Nardelli, Z. Ma, R. R. Reich, E. Padron and A. F. List, Phase 2 trial of Smoothened (SMO) inhibitor PF-04449913 (PF-04) in refractory myelodysplastic syndromes (MDS), Blood 128 (2016) 3174-3174; https://doi. org/10.1182/blood.V128.22.3174.3174

79. D. A. Sallman, R. S. Komrokji, K. L. Sweet, Q. Mo, K. L. McGraw, V. H. Duong, L. Zhang, L. A. Nardelli, E. Padron, A. F. List and J. E. Lancet, A phase 2 trial of the oral smoothened inhibitor glasdegib in refractory myelodysplastic syndromes (MDS), Leuk. Res. 81 (2019) 56-61; https://doi. org/10.1016/j.leukres.2019.03.008

80. A. M. Zeidan, M. W. Schuster, J. Krauter, J. A. Maertens, E. Gyan, M. Joris, T. F. Menne, P. Vyas, W. W. Ma, A. O'Connell, M. Zeremski, A. Kudla, G. Chan and M. A. Sekeres, Clinical benefit of glasdegib in combination with azacitidine or low-dose cytarabine in patients with acute myeloid leukemia, Blood 134 (2019) 3916-3916; https://doi.org/10.1182/blood-2019-124034

81. A. Kent, S. Vasu, D. Schatz, N. Monson, S. Devine, C. Smith, J. A. Gutman and D. A. Pollyea, Glasdegib as maintenance therapy for patients with AML and MDS patients at high risk for postallogeneic stem cell transplant relapse, Blood Adv. 4 (2020) 3102-3108; https://doi.org/10.1182/bloodadvances.2020001991

82. J. E. Cortes, H. Dombret, A. A. Merchant, T. Tauchi, C. DiRienzo, M. Zeremski, B. Sleight, X. Zhang, M. N. Shaik, T. Bell, G. Chan and M. A. Sekeres, Phase 3, randomized, placebo-controlled trials evaluating glasdegib in combination with intensive or nonintensive chemotherapy in patients with untreated acute myeloid leukemia, J. Clin. Oncol. 36 (2018) TPS7073-TPS7073; https:// doi.org/10.1200/JCO.2018.36.15_suppl.TPS7073

83. J. E. Cortes, H. Dombret, A. Merchant, T. Tauchi, C. G. DiRienzo, B. Sleight, X. Zhang, E. P. Leip, N. Shaik, T. Bell, G. Chan and M. A. Sekeres, Glasdegib plus intensive/nonintensive chemotherapy in untreated acute myeloid leukemia: BRIGHT AML 1019 Phase III trials, Future Oncol. 15 (2019) 3531-3545; https://doi.org/10.2217/fon-2019-0373

84. S. Lin, M. Shaik and A. Ruiz, Population pharmacokinetics of glasdegib in patients with advanced hematologic and solid tumors (in "American Society for Clinical Pharmacology and Therapeutics - Abstracts of 2018 Annual Meeting"), Clin. Pharmacol. Ther. 103 (Suppl 1) (2018) S78; https://doi. org/10.1002/cpt.993

85. S. Lin, N. Shaik, G. Martinelli, A. J. Wagner, J. Cortes and A. Ruiz-Garcia, Population pharmacokinetics of glasdegib in patients with advanced hematologic malignancies and solid tumors, $J$. Clin. Pharmacol. (2019); https://doi.org/10.1002/jcph.1556

86. N. Shaik, B. Hee, Y. Liang and R. R. LaBadie, Absolute oral bioavailability of glasdegib (PF04449913), a Smoothened inhibitor, in randomized healthy volunteers, Clin. Pharmacol. Drug Dev. 8 (2019) 895-902; https://doi.org/10.1002/cpdd.692

87. N. Giri, L. H. Lam, R. R. LaBadie, J. F. Krzyzaniak, H. Jiang, B. Hee, Y. Liang and M. N. Shaik, Evaluation of the effect of new formulation, food, or a proton pump inhibitor on the relative bioavailability of the Smoothened inhibitor glasdegib (PF-04449913) in healthy volunteers, Cancer Chemother. Pharmacol. 80 (2017) 1249-1260; https://doi.org/10.1007/s00280-017-3472-9

88. N. Shaik, B. Hee, H. Wei and R. R. LaBadie, Evaluation of the effects of formulation, food, or a proton-pump inhibitor on the pharmacokinetics of glasdegib (PF-04449913) in healthy volunteers: a randomized phase I study, Cancer Chemother. Pharmacol. 83 (2019) 463-472; https://doi.org/10.1007/ s00280-018-3748-8 
89. J. L. Lam, A. Vaz, B. Hee, Y. Liang, X. Yang and M. N. Shaik, Metabolism, excretion and pharmacokinetics of $\left[{ }^{14} \mathrm{C}\right]$ glasdegib (PF-04449913) in healthy volunteers following oral administration, Xenobiotica Fate Foreign Compd. Biol. Syst. 47 (2017) 1064-1076; https://doi.org/10.1080/00498254.20 16.1261307

90. M. N. Shaik, R. R. LaBadie, D. Rudin and W. J. Levin, Evaluation of the effect of food and ketoconazole on the pharmacokinetics of the Smoothened inhibitor PF-04449913 in healthy volunteers, Cancer Chemother. Pharmacol. 74 (2014) 411-418; https://doi.org/10.1007/s00280-014-2502-0

91. European Medicines Agency, Glasdegib (DAURISMO): EPAR - Product Information, https:// www.ema.europa.eu/en/documents/product-information/daurismo-epar-product-information en.pdf (accessed 10 October 2020).

92. M. N. Shaik, B. Hee, H. Wei and R. R. LaBadie, Evaluation of the effect of rifampin on the pharmacokinetics of the Smoothened inhibitor glasdegib in healthy volunteers, Br. J. Clin. Pharmacol. 84 (2018) 1346-1353; https://doi.org/10.1111/bcp.13568

93. A. Ruiz-Garcia, N. Shaik, S. Lin, C. Jamieson, M. Heuser and G. Chan, Evaluation of the relationship of glasdegib exposure and safety end points in patients with refractory solid tumors and hematologic malignancies, J. Clin. Pharmacol. (2020) jcph.1742; https://doi.org/10.1002/jcph.1742

94. M. Tavares, S. Chacim and J. M. Mariz, Compassionate use of glasdegib in combination with low-dose cytarabine for relapsed, refractory acute myeloid leukemia or high-risk myelodysplastic syndrome, Ann. Hematol. (2020); https://doi.org/10.1007/s00277-020-04291-0

95. N. Shaik, L. Mendes da Costa, B. Hee, Y. Liang and R. R. LaBadie, A thorough QT study to evaluate the effect of glasdegib on cardiac repolarization in healthy adult subjects (in "Abstracts for the Ninth American Conference on Pharmacometrics (ACoP9)"), J. Pharmacokinet. Pharmacodyn. 45 (2018) S87 [Abstract no. T-092]; https://doi.org/10.1007/s10928-018-9606-9

96. J. C. Masters, N. Shaik, L. Mendes da Costa, B. Hee and R. R. LaBadie, Clinical and model-based evaluation of the effect of glasdegib on cardiac repolarization from a randomized thorough QT study, Clin. Pharmacol. Drug Dev. (2020) cpdd.862; https://doi.org/10.1002/cpdd.862

97. N. Sarapa and M. R. Britto, Challenges of characterizing proarrhythmic risk due to QTc prolongation induced by nonadjuvant anticancer agents, Expert Opin. Drug Saf. 7 (2008) 305-318; https:// doi.org/10.1517/14740338.7.3.305

98. E. Park, J. Willard, D. Bi, M. Fiszman, D. Kozeli and J. Koerner, The impact of drug-related QT prolongation on FDA regulatory decisions, Int. J. Cardiol. 168 (2013) 4975-4976; https://doi. org/10.1016/j.ijcard.2013.07.136

99. R. J. Lipinski, P. R. Hutson, P. W. Hannam, R. J. Nydza, I. M. Washington, R. W. Moore, G. G. Girdaukas, R. E. Peterson and W. Bushman, Dose- and route-dependent teratogenicity, toxicity, and pharmacokinetic profiles of the hedgehog signaling antagonist cyclopamine in the mouse, Toxicol. Sci. 104 (2008) 189-197; https://doi.org/10.1093/toxsci/kfn076

100. E. Morinello, M. Pignatello, L. Villabruna, P. Goelzer and H. Bürgin, Embryofetal development study of vismodegib, a Hedgehog pathway inhibitor, in rats, Birth Defects Res. B. Dev. Reprod. Toxicol. 101 (2014) 135-143; https://doi.org/10.1002/bdrb.21093

101. Glasdegib, Drugs Lact. Database Lact. Bethesda (MD): National Library of Medicine (US); Retrieved from http://www.ncbi.nlm.nih.gov/books/NBK535600/

102. S. V. Mohan and A. L. S. Chang, Management of cutaneous and extracutaneous side effects of smoothened inhibitor therapy for advanced basal cell carcinoma, Clin. Cancer Res. 21 (2015) 2677-2683; https://doi.org/10.1158/1078-0432.CCR-14-3180

103. M. E. Lacouture, B. Dréno, P. A. Ascierto, R. Dummer, N. Basset-Seguin, K. Fife, S. Ernst, L. Licitra, R. I. Neves, K. Peris, S. Puig, J. Sokolof, A. Sekulic, A. Hauschild and R. Kunstfeld, Characterization and management of hedgehog pathway inhibitor-related adverse events in patients 
with advanced basal cell carcinoma, The Oncologist 21 (2016) 1218-1229; https://doi.org/10.1634/ theoncologist.2016-0186

104. A. A. Jacobsen, A. R. Kydd and J. Strasswimmer, Practical management of the adverse effects of Hedgehog pathway inhibitor therapy for basal cell carcinoma, J. Am. Acad. Dermatol. 76 (2017) 767-768; https://doi.org/10.1016/j.jaad.2016.04.063

105. X. Song, Y. Peng, X. Wang, Y. Chen, L. Jin, T. Yang, M. Qian, W. Ni, X. Tong and J. Lan, Incidence, survival, and risk factors for adults with acute myeloid leukemia not otherwise specified and acute myeloid leukemia with recurrent genetic abnormalities: analysis of the surveillance, epidemiology, and end results (SEER) database, 2001-2013, Acta Haematol. 139 (2018) 115-127; https:// doi.org/10.1159/000486228

106. German-Austrian AML Study Group (AMLSG), G. Nagel, D. Weber, E. Fromm, S. Erhardt, M. Lübbert, W. Fiedler, T. Kindler, J. Krauter, P. Brossart, A. Kündgen, H. R. Salih, J. Westermann, G. Wulf, B. Hertenstein, M. Wattad, K. Götze, D. Kraemer, T. Heinicke, M. Girschikofsky, H. G. Derigs, H. A. Horst, C. Rudolph, M. Heuser, G. Göhring, V. Teleanu, L. Bullinger, F. Thol, V. I. Gaidzik, P. Paschka, K. Döhner, A. Ganser, H. Döhner, R. F. Schlenk and the German-Austrian AML Study Group (AMLSG), Epidemiological, genetic, and clinical characterization by age of newly diagnosed acute myeloid leukemia based on an academic population-based registry study (AMLSG BiO), Ann. Hematol. 96 (2017) 1993-2003; https://doi.org/10.1007/s00277-017-3150-3

107. X. Thomas and M. Heiblig, An evaluation of glasdegib for the treatment of acute myelogenous leukemia, Expert Opin. Pharmacother. 21 (2020) 523-530; https://doi.org/10.1080/14656566.2020.171 3094

108. N. Daver, A. H. Wei, D. A. Pollyea, A. T. Fathi, P. Vyas and C. D. DiNardo, New directions for emerging therapies in acute myeloid leukemia: the next chapter, Blood Cancer J. 10 (2020) 107; https://doi.org/10.1038/s41408-020-00376-1

109. J. E. Cortes, A. Candoni, R. E. Clark, B. Leber, P. Montesinos, P. Vyas, A. M. Zeidan and M. Heuser, Selection and management of older patients with acute myeloid leukemia treated with glasdegib plus low-dose cytarabine: expert panel review, Leuk. Lymphoma (2020) 1-19; https://doi.org /10.1080/10428194.2020.1817445

110. J. C. Masters, R. R. LaBadie, J. Salageanu, J. Li and N. Shail, Pharmacokinetics and safety of glasdegib in participants with moderate/severe hepatic impairment: a phase I, single-dose, matched case-control study, Clin. Pharmacol. Drug Dev. (2020); https://doi.org/ 10.1002/cpdd.897.

111. N. Shaik, R. LaBadie, B. Hee and G. Chan, Evaluation of the impact of renal impairment on the pharmacokinetics of glasdegib, Clin. Pharmacol. Ther. 107 (2020) (S1) S69-S69 [Abstract no. PII126]; https://doi.org/10.1002/cpt.1732

112. H. A. Pham, S. Milev, S. Li, D. Zou, Y. Hu, B. Heeg and T. J. Bell, Budget impact of glasdegib in combination with low-dose cytarabine for the treatment of first-line acute myeloid leukemia in the United States, Blood 134 (2019) 5852-5852; https://doi.org/10.1182/blood-2019-122709

113. S. R. Goldsmith, A. R. Lovell and M. A. Schroeder, Glasdegib for the treatment of adult patients with newly diagnosed acute myeloid leukemia or high-grade myelodysplastic syndrome who are elderly or otherwise unfit for standard induction chemotherapy, Drugs Today 55 (2019) 545; https://doi.org/10.1358/dot.2019.55.9.3020160

114. R. M. Shallis, N. A. Podoltsev, T. Prebet and A. M. Zeidan, Trial in progress: Glad-AML - a randomized, phase 2 trial of glasdegib with two standard decitabine regimens for older patients with newly-diagnosed, poor-risk acute myeloid leukemia, Blood 136 (2020) 29-29; https://doi. org/10.1182/blood-2020-139428 